\title{
TURNING THEIR PAIN TO GAIN: CHARISMATIC LEADER INFLUENCE ON FOLLOWER STRESS APPRAISAL AND JOB PERFORMANCE
}

\author{
MARCIE A. LEPINE \\ Arizona State University \\ YIWEN ZHANG \\ University of Hong Kong \\ EEAN R. CRAWFORD \\ University of Iowa \\ BRUCE LOUIS RICH \\ California State University San Marcos
}

\begin{abstract}
We develop and test a theoretical model that explores how individuals appraise different types of stressful job demands and how these cognitive appraisals impact job performance. The model also explores how charismatic leaders influence such appraisal and reaction processes, and, by virtue of these effects, how leaders can influence the impact of stressful demands on their followers' job performance. In Study 1 ( $n=74$ U.S. Marines), our model was largely supported in hierarchical linear modeling analyses. Marines whose leaders were judged by superiors to exhibit charismatic leader behaviors appraised challenge stressors as being more challenging, and were more likely to respond to this appraisal with higher performance. Although charismatic leader behaviors did not influence how hindrance stressors were appraised, they negated the strong negative effect of hindrance appraisals on job performance. In Study 2 ( $n=270$ U.S. Marines), charismatic leader behaviors were measured through the eyes of the focal Marines, and the interactions found in Study 1 were replicated. Results from multilevel structural equation modeling analyses also indicate that charismatic leader behaviors moderate both the mediating role of challenge appraisals in transmitting the effect of challenge stressors to job performance and the mediating role of hindrance appraisals in transmitting the effect of hindrance stressors to job performance. Implications of our results to theory and practice are discussed.
\end{abstract}

Although scholars and writers in the business press have predominantly focused on the negative effects of workplace stress (Overman, 2011; Stroud, 2008), researchers have begun to paint a picture of stress in the workplace that is more balanced. Drawing from research in the medical and psychological fields-specifically, Hans Selye's (1956) notion that certain stressful demands may be inherently satisfying to humans and the early findings of Yerkes and Dodson (1908) that arousal may be beneficial up to some point-researchers have expanded upon Lazarus and Folkman's (1984) transactional theory of stress to reconcile the negative consequences

We thank editor Amy Colbert and three anonymous reviewers for their efforts in developing and improving this manuscript. of workplace stress with some potential positives (e.g., Cavanaugh, Boswell, Roehling, \& Boudreau, 2000; Jex, 1998). According to the transactional theory of stress, stress may have negative or positive implications for the individual depending on how the demands that evoke the stress process are believed to affect personal growth, development, and well-being-demands can be appraised as benign, harmful, or threatening, or they can be appraised as a challenge or opportunity (Lazarus \& Folkman, 1984).

While the theory purports that the meaning of demands vary among individuals, Cavanaugh and colleagues (2000) argued that, despite individual differences, certain job demands can be divided into two broad categories-hindrance stressors and challenge stressors-which are positively but modestly 
correlated, and, most importantly, differentially related to several important employee outcomes. Many studies have since applied this framework and concluded that, while both hindrance and challenge stressors are associated with higher strain, the dimensions have differential effects on a wide variety of attitudinal, emotional, motivational, and performancebased outcomes (Boswell, Olson-Buchanan, \& LePine, 2004; Crawford, LePine, \& Rich, 2010; LePine, LePine, \& Jackson, 2004; LePine, Podsakoff, \& LePine, 2005; Pearsall, Ellis, \& Stein, 2009; Podsakoff, LePine, \& LePine, 2007; Rodell \& Judge, 2009; Wallace, Edwards, Arnold, Frazier, \& Finch, 2009; Webster, Beehr, \& Christiansen, 2010; Webster, Beehr, \& Love, 2011).

Although the challenge-hindrance stressor framework has advanced our understanding of the differential effects of demands on important organizational outcomes, our theoretical understanding of the effects of challenge and hindrance stressors on the appraisal process (the meaning of the demands for individuals) is far from complete. Beyond directly assessing the theoretical explanation of why challenge and hindrance stressors influence outcomes the way they do, the relationship between challenge and hindrance stressors and the appraisal of those stressors is important because appraisals could be influenced by outside factors in such a way that the entire stress process is altered (Lazarus \& Folkman, 1984). More specifically, we could potentially identify factors that moderate the role of appraisals as transmitters of stressor effects, and, in the end, significantly impact how stressors influence outcomes. Understanding the role of these factors would have practical implications for managing stress as well.

To this end, we consider the role that leaders can have in influencing the stress process through affecting how followers both appraise and respond to different stressors. We know, for example, that certain leader behaviors such as abusive supervision and laissez-faire leadership may serve as stressors, and thus may be associated with higher levels of perceived stress and strain in those leaders' followers (e.g., abusive leadership, Tepper, 2000; laissez-faire leadership, Skogstad, Einarsen, Torsheim, Aasland, \& Hetland, 2007). We also know that positive leader behaviors, such as support, trust, and other similar behaviors, are associated with lower levels of perceived stress and that such behaviors may lead to emotional and motivational resources that can be used to cope with stress (e.g., Firth, Mellor, Moore, \& Loquet, 2003; Skakon, Nielsen, Borg, \& Guzman, 2010; van Dierendonck, Haynes, Borrill, \& Stride, 2004; Wallace et al., 2009).
What we lack, however, is a clear understanding of how leaders might influence followers' stress in other ways. It is possible, for example, that certain types of leaders manage the meaning of follower stress, and thereby influence how followers appraise stressful demands, or influence how followers react to their appraisal, or both. Because leaders have the ability to influence followers' perceptions of their environment (e.g., Piccolo \& Colquitt, 2006), it is possible that leaders might be able to amplify the tendency of followers to see the positive side of challenge stressors (Crum, Salovey, \& Achor, 2013), consequently increasing the positive outcomes. Similarly, leaders could mitigate the tendency of followers to see the negative side of hindrance stressors (Lazarus \& Folkman, 1984), consequently decreasing negative outcomes.

In essence, what we are suggesting is that leaders can turn followers' perceptions of stressor pain to performance gain. Our twist on the issue, and the overarching goal of our research, is to understand how leadership engenders more beneficial stressor appraisal among followers with respect to two categories of stressful job demands and their ultimate impact on follower job performance. In this regard, we focus on charismatic leaders, who differ from other leaders through their ability to formulate and articulate an inspirational vision and by exhibiting actions that create an impression that they and their mission are extraordinary (Conger \& Kanungo, 1987, 1994; Crant \& Bateman, 2000; House, 1977; House \& Shamir, 1993; Shamir, Zakay, Breinin, \& Popper, 1998). In the present research, we develop theory that considers charismatic leaders' capacity to shape the feelings and thoughts of followers (e.g., Crum et al., 2013; Erez, Misangyi, Johnson, LePine, \& Halverson, 2008; Piccolo \& Colquitt, 2006), in order to resolve the important question of whether this type of influence might be strong enough to impact how work stressors influence follower contributions to organizational effectiveness, and, just as important, why this occurs.

\section{THE STRESS PROCESS AND PERFORMANCE}

Based on the transactional theory of stress, we define "stress" as a process set into motion when demands in the environment tax or exceed an individual's resources (Lazarus \& Folkman, 1984). These demands are then appraised as irrelevant or as an opportunity for or obstacle to personal growth, development, and well-being (primary appraisal; Lazarus \& Folkman, 1984). Lastly, the response to the 
appraisal is determined by a judgment that is made as to whether an action can be taken to improve the stressful situation through various coping mechanisms (secondary appraisal; Lazarus \& Folkman, 1984). Extending Lazarus and Folkman's theory of stress, Cavanaugh et al. (2000) developed the challenge-hindrance stressor framework to explain differential stressor relationships with outcomes. In this framework, "challenge stressors" refers to job demands that present the potential for personal growth and rewards (Cavanaugh et al., 2000; Crawford et al., 2010; LePine et al., 2005). Job demands that have been identified as such include workload, time pressure, job complexity, and responsibility (LePine et al., 2005; Webster et al., 2011; Zhang, LePine, Buckman, \& Wei, 2014). "Hindrance stressors" refers to job demands that do not present the potential for personal growth and rewards, and may actually thwart growth or gains (Cavanaugh et al., 2000; Crawford et al., 2010; LePine et al., 2005). Job demands that have been identified as such include administrative hassles, role ambiguity, role conflict, resource inadequacies, interpersonal conflict, and organizational politics (LePine et al., 2005; Webster et al., 2011; Zhang et al., 2014).

Investigations adopting this framework confirm that challenge and hindrance stressors are positively related to strain and burnout, but relationships with work attitudes, emotions, engagement, and motivation differ as a function of the stressors. These differential effects, in turn, influence job performance in contrasting ways. Meta-analyses offer support for the differential relationships between challenge and hindrance stressors and work attitudes (Podsakoff et al., 2007), engagement (Crawford et al., 2010), motivation (LePine et al., 2005), and individual performance (LePine et al., 2005). Recent studies offer support for the differential relationships between challenge and hindrance stressors and citizenship and counterproductive behaviors through emotions (Rodell \& Judge, 2009) as well as for differential relationships between challenge and hindrance stressors and team performance (Pearsall et al., 2009). In summary, research acknowledging that both challenge and hindrance stressors exhibit positive relationships with strains finds that challenge stressors exhibit positive relationships with individual and team performance, while hindrance stressors exhibit negative relationships with individual and team performance through differential attitudinal, motivational, and emotional responses.

As research support builds for the challengehindrance framework, a significant gap is emerging that must be addressed if we are to fully understand the stress process and the impact that organizations may have on that process. Although the appraisal process is implicit in the challenge-hindrance stressor framework and validation studies have generally supported the assumption that challenge stressors are appraised as challenging and hindrance stressors are appraised as hindering (Cavanaugh et al., 2000; LePine et al., 2005; Rodell \& Judge, 2009), what we do not know is whether there are conditions or circumstance under which challenge stressors may be appraised as more or less challenging, or hindrance stressors as more or less hindering, and how the challenge or hindrance appraisal then affects reactions and, ultimately, outcomes.

Although no studies have specifically examined factors that may affect the appraisals of challenge and hindrance stressors, studies examining moderators of the challenge-hindrance stressor outcome relationship provide insight into this limitation. Wallace et al. (2009) and Zhang et al. (2014) examined organizational support and leadership, respectively, as moderators between challenge and hindrance stressors and performance. Wallace and colleagues (2009) found that organizational support moderated the relationship between challenge stressors and role-based performance, but, unexpectedly, not between hindrance stressors and rolebased performance. Zhang and colleagues (2014) found that transformational leaders enhanced the positive effect of challenge stressors on job performance through the strengthening of the positive relation between challenge stressors and justice perceptions, but, unexpectedly, had no effect on the relationship between hindrance stressors and job performance. The authors note that a comprehensive understanding of the challenge-hindrance stressor-appraisal process (the relationship between stressors and appraisals, and moderators of that relationship) would offer insight into these findings and provide a significant theoretical contribution to the challenge-hindrance stressor framework and the stress literature, in general.

Although studies have examined felt challenge (Boswell et al., 2004) and challenge appraisals (Ohly \& Fritz, 2010), to our knowledge, only one study has addressed both challenge and hindrance appraisals within the challenge-hindrance framework. Webster and colleagues (2011) examined whether individual demands categorized as "challenges" (workload and responsibility) and "hindrances" (role conflict and role ambiguity) were generally appraised as such. They found support for the 
assumption that demands categorized as challenges were generally appraised as challenges and demands categorized as hindrances were generally appraised as hindrances, but also found that some demands could be appraised as both to varying degrees. We build upon the work of Webster et al. (2011) and develop theory that underscores the importance of examining primary appraisal in the challengehindrance stress process (i.e., the meaning of challenge and hindrance demands for individuals) and the potential significance of identifying the mechanism by which challenge and hindrance appraisals are influenced.

To examine the primary appraisal process, and in a departure from previous challenge-hindrance stressor research, we conceptually distinguish the demand - the challenge and hindrance stressorfrom its appraisal. According to transactional stress theory (Lazarus \& Folkman, 1984: 24), demands or events should be considered in terms of their significance to the individual because "how a person construes an event shapes the emotional and behavioral response." Therefore, while challenge stressors refer to the presence of challenge demands, challenge appraisals refer to an individual's subjective interpretation that the demands have a potential for personal gain, growth, development, and well-being. Given that challenge appraisals are more likely when there is a sense that an investment in time and energy will be rewarded in the demanding environment (Crawford et al., 2010; Lazarus \& Folkman, 1984), "challenge stressors" (characterized as demands with the potential for growth and rewards) likely elicit challenge appraisals. Moreover, while hindrances stressors refer to the presence of hindrance demands, hindrance appraisals refer to an individual's subjective interpretation that the demands have a potential to result in personal loss, constraints, or harm. Hindrance appraisals are more likely when it is difficult to determine whether an investment of time and energy will be rewarded, and, thus, "hindrance stressors" (characterized as demands with the lack of potential for growth and rewards and/or that may actually thwart growth or gains) likely elicit hindrance appraisals. As mentioned, validation studies have shown that challenge stressors are generally perceived as challenging and hindrance stressors are generally perceived as hindering (Cavanaugh et al., 2000; LePine et al., 2005; Rodell \& Judge, 2009). However, the relationship of challenge and hindrance appraisals as mediators of the relationship between challenge and hindrance stressors and performance has not been explicitly examined. Therefore, we offer two general hypotheses that provide the foundation for our research:

Hypothesis 1a. Challenge appraisals will mediate the relationship between challenge stressors and task performance.

Hypothesis $1 b$. Hindrance appraisals will mediate the relationship between hindrance stressors and task performance.

In the next section, we consider why and how charismatic leadership may affect both the appraisal of stressors and the reaction to stressors that ultimately affect the relationships between stressor demands and performance.

\section{THE INFLUENCE OF CHARISMATIC LEADERSHIP ON THE STRESS PROCESS}

We propose that charismatic leaders affect both the appraisal of and response to challenge and hindrance stressors. Charismatic leadership behaviors are found at the highest end of the full range model of leadership (see Avolio, 2004, for a comprehensive discussion of the model), which describes leadership behaviors ranging from laissez-faire leadership, seen as the absence of leadership in which the leader avoids making decisions, abdicates responsibility, and does not use their authority; to transactional leadership, based on the leader setting objectives and monitoring and controlling outcomes; to transformational leadership, in which the leader proactively raises follower awareness for transcendent collective interests and helps followers achieve extraordinary goals (Antonakis, Avolio, \& Sivasubramaniam, 2003; Bass, 1985, 1990; Bass \& Avolio, 1995; Bass \& Riggio, 2006; Fuller, Patterson, Hester, \& Stringer, 1996; Lowe, Kroeck, \& Sivasubramaniam, 1996). Operationally, charismatic leadership is most frequently examined as a combination of the idealized influence and inspirational motivation components of transformational leadership (Bass, 1998; Bass \& Avolio, 1993; van Knippenberg \& Sitkin, 2013). "Idealized influence" refers to actions of the leader that are centered on communicating values, beliefs, and a sense of purpose, meaningfulness, and mission. "Inspirational motivation" refers to the ways leaders energize their followers by viewing the future with optimism and enthusiasm, stressing ambitious goals, and communicating to followers that the vision is achievable (Antonakis et al., 2003; Bass, 1985).

Charismatic leader behaviors are specific and observable, including serving as role models, challenging 
followers with high standards that are intrinsically motivating, communicating optimism about future goal attainment, and expressing confidence that goals will be achieved (Bass, 1985; Judge \& Piccolo, 2004). These are discretionary behaviors under the leaders' control, observable by superiors and followers, and, through these behaviors, charismatic leaders increase follower attentiveness to goals, selfefficacy, and optimism (Bass, 1998; House \& Howell, 1992; Shamir, House, \& Arthur, 1993).

Scholars considering the impact that leaders have on follower stress have focused on how leaders create or influence the perceived level of demands or stressors faced by followers (Skakon, et al., 2010; Skogstad et al., 2007; Tepper, 2000). However, although it has not been specifically tested, it is also possible that charismatic leaders influence both the appraisal of demands as challenging or hindering as well as reactions to those appraisals (Lazarus \& Folkman, 1984). For example, leaders may influence followers' stress mindsets (Crum et al., 2013) or the meaning that followers derive from their job demands (Arnold, Turner, Barling, Kelloway, \& McKee, 2007; Piccolo \& Colquitt, 2006). As charismatic leaders frame job demands in an optimistic light and serve as role models to followers regarding appropriate reactions, follower appraisals of stressful demands are more apt to evoke challenge and less inclined to evoke feelings of hindrance. Moreover, followers should feel more confident about responding to the stressful demands. We will expound on these relationships more carefully in the next two sections.

\section{Influence of Charismatic Leader Behaviors on Stressor Appraisals}

We draw from recent research on the management of mindsets and meaning (Crum et al., 2013; Piccolo \& Colquitt, 2006) to propose that charismatic leaders, by managing the meaning of stressors, may have an impact on the appraisal of the stressor as challenging or hindering. Crum and colleagues (2013) explored the role of mindsets on the effects of stress and found that one's stress mindset can be managed from a stress-is-debilitating mindset to a stress-isenhancing one. It is likely that charismatic leaders, through their optimism, enthusiasm, and purposedriven focus, do the same by managing the message that is delivered to followers when faced with stressors. Indeed, Piccolo and Colquitt (2006) found that followers of truly exceptional leaders regarded their jobs as more challenging and important through higher perceived levels of Hackman and Oldham's (1974) five core job characteristics.

Charismatic leadership may play a particularly important role in the management of the meaning of challenge stressors. That is, we suggest that charismatic leaders emphasize a stress-is-enhancing mindset and thereby manage the meaning of challenge stressors by facilitating perceptions of the intrinsically rewarding characteristics of these demands or focusing attention on key tasks that must be accomplished, thus fostering perceptions that challenge stressors reflect opportunities that can be realized (Courtright, Colbert, \& Choi, 2014; Crum et al., 2013; Hunter \& Thatcher, 2007; Piccolo \& Colquitt, 2006). Indeed, charismatic leaders may accentuate a stress-is-enhancing mindset by communicating optimism about future goal attainment and by helping followers envision attractive future states. Job demands that present the potential for personal growth and rewards (e.g., time pressure, workload, responsibility, and complexity), but that are taxing and difficult to overcome, may now be perceived as worth the extra effort of time and energy (Piccolo \& Colquitt, 2006).

We also suggest that charismatic leaders will change a stress-is-debilitating mindset to a stress-isenhancing one and thereby manage the meaning of hindrance stressors, reducing followers' tendencies to appraise hindrance stressors as threats (Crum et al., 2013; Piccolo \& Colquitt, 2006). Job demands that lack the potential for growth and rewards, or that may even thwart growth or gains, often indicate situations of ambiguity (e.g., role ambiguity, role conflict) or inefficiency (e.g., administrative hassles, office politics), of which charismatic leaders are thought to be particularly effective at managing (Shamir \& Howell, 1999). By maintaining a strong sense of purpose, focusing attention on the collective mission, and remaining confident that goals can be achieved despite obstacles, charismatic leaders act as role models for how followers might reevaluate hindering situations (Lazarus \& Folkman, 1984) so as to weaken the perception that they are threatening (Kets de Vries, 1997; Shamir \& Howell, 1999). As a result, followers with charismatic leaders should have a reduced tendency to appraise even threatening demands as hindrances.

Hypothesis 2a. Charismatic leadership moderates the positive relationship between challenge stressors and challenge appraisals such that the relationship is more positive for those whose leaders are more charismatic. 
Hypothesis 2b. Charismatic leadership moderates the positive relationship between hindrance stressors and hindrance appraisals such that the relationship is less positive for those whose leaders are more charismatic.

\section{Influence of Charismatic Leader Behaviors on Reactions to Stressor Appraisals}

The reaction to an appraised stressor is an evaluation of whether to address the demands of the stressor directly through strategizing and increasing effort (e.g., problem-focused coping) or by minimizing negative emotions through emotional expression, support, or avoidance (e.g., emotion-focused coping; Lazarus \& Folkman, 1984). Research has not specifically examined moderators of the relationship between challenge and hindrance appraisals and performance. However, research in other areas (i.e., felt stress and developmental challenges) has uncovered potential relationships of importance. Hunter and Thatcher (2007) found that employees with higher levels of affective commitment and more work experience "channeled" felt stress more effectively into sales performance by directing their concentration toward tasks that were important. Courtright and colleagues (2014) found that leadership self-efficacy was important for the benefits of developmental challenges to be realized, given the relationship of developmental challenges with both engagement and exhaustion.

We build upon this research by specifically examining the moderating effect of charismatic leader behaviors on the relationship between challenge and hindrance appraisals and performance. We suggest that charismatic leaders provide emotional and motivational resources to followers to help meet the demands of the challenge- and hindrance-appraised stressors. This is consistent with Hobfoll's (1989) conservation of resources theory suggesting that people strive to retain, protect, and build resources that are threatened in times of stress. In this vein, we argue that the behaviors displayed by a charismatic leader serve as a resource to accentuate positive follower reactions and buffer negative follower reactions to stress.

We acknowledge that challenge stressors are associated with both strain and pleasurable emotional reactions such as eagerness, excitement, and attentiveness, and positive motivational states such as self-efficacy, perceived goal congruence, and engagement (Courtright et al., 2014; Crawford et al., 2010; Lazarus \& Folkman, 1984; LePine et al., 2005;
Pearsall et al., 2009; Rodell \& Judge, 2009; Shamir et al., 1993). Investigators have documented the occurrence of stress-related growth, in which experienced stress enhances the development of mental toughness, heightened awareness, new perspectives, a sense of mastery, and strengthened priorities (Crum et al., 2013; Park \& Helgeson, 2006; Tedeschi \& Calhoun, 2004). We propose that charismatic leaders will enhance followers' positive emotional reactions to challenge appraisals as they role model optimism, enthusiasm, and confidence (Bono, Foldes, Vison, \& Muros, 2007; Bono \& Ilies, 2006). Prior research on emotional contagion in groups supports the notion that positive emotions expressed by one group member transfer to other members to improve cooperation, decrease conflict, and increase performance (Barsade, 2002). Moreover, employees who report to leaders who engage in transformational leadership behaviors experience more optimism, happiness, and enthusiasm than employees who report to leaders who do not engage in these behaviors (Bono et al., 2007; Erez et al., 2008). We expect a charismatic leader's positive emotional displays to serve the same function by boosting followers' emotional resources, which in turn are harnessed to improve their own task performance.

While charismatic leaders will enhance positive emotional reactions, they may also provide motivational resources that help followers cope with challenging demands (Crum et al., 2013; Detert \& Burris, 2007; Rodell \& Judge, 2009; Seltzer, Numerof, \& Bass, 1989; Sosik \& Godshalk, 2000). Charismatic leaders' expressed confidence that outcomes are achievable can build task-specific self-efficacy among followers and collective efficacy among teams (Courtright et al., 2014; Lyons \& Schneider, 2009; Walumbwa, Wang, Lawler, \& Shi, 2004). Overall, the charismatic leader behaviors serve to increase follower expectancy and overall motivation by eliciting the belief that one can overcome the challenges and achieve the desired outcome (LePine et al., 2005). In summary, by exerting positive influences on follower affective and motivational states, charismatic leaders provide the resources needed to enhance the positive link between followers' challenge appraisals and task performance.

Although hindrance stressors negatively influence job performance because they induce unpleasant emotions such as anger and frustration, negative motivational states such as disengagement and low self-confidence, and strains such as anxiety and frustration (Lazarus \& Folkman, 1984; LePine et al., 2005; Rodell \& Judge, 2009), charismatic leaders may induce an overall positive effect on the 
reaction. As discussed above, charismatic leader expressions of optimism, enthusiasm, and confidence can result in a transfer of these positive states to followers (Barsade, 2002; Bono et al., 2007; Erez et al., 2008), thus ameliorating negative effects of hindrance appraisals on affective and motivational states that more directly drive job performance. In addition, the broaden-and-build theory (Fredrickson, Mancuso, Branigan, \& Tugade, 2000) suggests that positive emotions speed recovery from, or actually undo, the psychological and physiological strain elicited by negative emotions, and ultimately return the body to mid-range levels of activation suitable for pursuing a wider range of behavioral options. The stress-is-enhancing mindset has similar physiological effects, returning the body to optimal levels of arousal and cortisol activity to effectively respond to the stressor (Crum et al., 2013).

Unpleasant emotions and negative motivational states may elicit a belief of harm and a drain of resources. However, charismatic leaders, by keeping focus on the importance of the mission, remaining confident that goals will be achieved, and, by providing affective and motivational resources, may increase expectancy by eliciting the belief in followers that they can overcome the hindrance and reach the desired outcome (Crum et al., 2013; Lazarus \& Folkman, 1984). In sum, charismatic leaders can buffer the detrimental effects of hindrance stressor appraisals on task performance because they can alleviate negative emotional, motivational, and strain-related states that more directly drive job performance.

Hypothesis 3a. Charismatic leadership moderates the positive relationship between challenge appraisals and task performance such that the relationship is more positive for those whose leaders are more charismatic.

Hypothesis 3b. Charismatic leadership moderates the negative relationship between hindrance appraisals and task performance such that the relationship is less negative for those whose leaders are more charismatic.

\section{Summary: An Integrated Model}

In this manuscript, we have hypothesized that charismatic leadership moderates the mediated stressor-job performance relationship. Moderated mediation occurs "when the strength of an indirect effect depends on the level of some variable, or, in other words, when mediation relations are contingent on the level of a moderator" (Preacher, Rucker, \& Hayes, 2007: 193).

For both types of stressors, charismatic leadership moderates both the appraisal process and the reaction process in a beneficial fashion, so the two specific moderation effects for each type of stressor add up to the overall moderated mediation effects.

Hypothesis 4a. Charismatic leadership moderates the positive indirect relationship of challenge stressors with task performance through challenge appraisals such that the relationship is more positive for those whose leaders are more charismatic.

Hypothesis 4b. Charismatic leadership moderates the negative indirect relationship of hindrance stressors with task performance through hindrance appraisals such that the effect is less negative for those whose leaders are more charismatic.

\section{METHOD}

\section{Study 1}

Sample and procedure. We collected data from four different ranks within the U.S. Marine Corps. One hundred and forty-nine currently enlisted Marines completed surveys about job stressors and appraisals. Participants were predominantly male $(95 \%)$ and had an average age of 21.59 years $(S D=$ $2.54)$. Less than half of the participants (40\%) attended college. The ranks of participants were Private First Class (PFC, 14\%), Lance Corporal (LCPL, 60\%), Corporal (CPL, 20\%), and Sergeant (SGT, 6\%). Participants had been enlisted for 26.41 months $(S D=$ 16.22) and had stayed in their current ranks for 10.51 months $(S D=8.41)$.

To ensure temporal precedence of independent variables in the proposed model (Cook \& Campbell, 1979), we collected ratings of Marine task performance from their unit leaders approximately three months after the initial survey. During these three months, some unit leaders were sent out for emergency overseas assignments, and, thus, we were able to obtain performance ratings for only 74 (out of 149) Marines from 33 unit leaders. Responses on focal study variables for the 74 Marines showed no significant differences from the responses of the Marines from the initial sample as compared to those for whom we did not receive performance ratings.

Measures. We measured challenge stressors and hindrance stressors with 20 items (10 items for each 
type) based on validated measures reported in prior research (Cavanaugh et al., 2000; LePine et al., 2004), meta-analytic categorizations of challenge and hindrance stressors (Crawford et al., 2010; LePine et al., 2005; Podsakoff et al., 2007), and research that has examined the dimensions of challenge and hindrance stressors (Podsakoff, 2007). Our items expand upon previous measures to be more inclusive of, or to more adequately represent, the conceptual domains of challenge and hindrance stressors (Cavanaugh et al., 2000; Zhang et al., 2014; see Appendix A for the full list). Challenge stressors included demands such as workload, work pace, time pressure, task complexity, accountability, and responsibility (e.g., "having to work very hard"). Hindrance stressors included demands such as administrative hassles, role ambiguity, role conflict, resource inadequacies, interpersonal conflict, and organizational politics (e.g., "conflicting requests from your supervisor(s)"). Participants evaluated the frequency of the 20 stressful demands in their daily work using a fivepoint Likert scale ranging from 1 for "never" to 5 for "extremely often."

We used two three-item measures for challenge appraisals and hindrance appraisals based on prior theory and research (Lazarus \& Folkman, 1984; LePine et al., 2005). We used the definitions and descriptions of the appraisal process described by Lazarus and Folkman (1984) and the items used by LePine and colleagues (2005) for their construct validity check (obtained through personal communication) to generate a set of items that map onto the appraisal of a stressful work demand as a challenge and as a hindrance. By using both theory and research to guide our item generation, we feel we adequately captured the construct of challenge and hindrance appraisals. After examining our set of items and eliminating those that were redundant (e.g., multiple items using similar wording of gains or losses), we were left with three items for challenge appraisals ("Working to fulfill the demands of my job helps to improve my personal growth and well-being," "I feel the demands of my job challenge me to achieve personal goals and accomplishment," and "In general, I feel that my job promotes my personal accomplishment") and three items for hindrance appraisals ("Working to fulfill the demands of my job thwarts my personal growth and well-being," "I feel the demands of my job constrain my achievement of personal goals and development," and "In general, I feel that my job hinders my personal accomplishment") that represent the definitions of challenge and hindrance (threat) appraisal and closely parallel the LePine et al. (2005) measures. Responses were collected using a five-point Likert scale ranging from 1 for "strongly disagree" to 5 for "strongly agree." The items and scales were structured such that, whereas high scores on the scales indicate appraisals that job demands are challenging and hindering, low scores on these scales indicate the relative absence of challenge and hindrance appraisals (respectively). We conducted confirmatory factor analyses for all the challenge/hindrance stressor and appraisal items in the employee survey. Results indicate that the proposed four-factor measurement model $\left(\chi^{2}[293]=698.29\right.$, comparative fit index $(\mathrm{CFI})=.91$, root mean square error of approximation (RMSEA) = .09, standardized root mean square residual (SRMR) $=.09$ ) fits the data significantly better than an alternative model with all challenge stressor and appraisal items loading on one factor and all hindrance stressor and appraisal items loading on another $\left(\chi^{2}[295]=956.47, \mathrm{CFI}=.85, \mathrm{RMSEA}=.13, \mathrm{SRMR}=\right.$ $\left..13 ; \Delta \chi^{2}[2]=258.18, p<.05\right)$ and another alternative model with all stressor items (challenges and hindrances) loading on one factor and all appraisal items loading on another $\left(\chi^{2}[295]=1239.48\right.$, CFI $=$ .79 , RMSEA $=.19$, SRMR $=.17 ; \Delta \chi^{2}[2]=521.19$, $p<.05)$.

Task performance refers to employee activities that are directly involved in or directly support the accomplishments of core job tasks (Borman \& Motowidlo, 1993). Unit leaders provided ratings of individual Marines' task performance using four items developed by Williams and Anderson (1991; e.g., “... adequately completes his/her assigned duties"). Responses were collected using a sevenpoint Likert scale ranging from 1 for "strongly disagree" to 7 for "strongly agree." We calculated intraclass correlation (ICC) for task performance to examine its independence. Results (ICC(1) $=0.32$, $\left.\chi^{2}[32]=64.29, p<.05\right)$ indicated the necessity of partitioning the variance of performance at both individual and unit levels. Because performance ratings were not normally distributed (skewness = -1.11, $S E=.28$; kurtosis $=1.57, S E=.34)$, we transformed them ( $Y$ to $Y^{\lambda} ; \lambda=1.625$ ) to bring skewness and kurtosis within the range of -1.0 and 1.0 (Mosteller \& Tukey, 1977).

We measured charismatic leadership with the combination of two subscales-idealized influence and inspirational motivation-from the Multifactor Leadership Questionnaire (MLQ-5X; Bass \& Avolio, 1995). Idealized influence was measured with four items that emphasized the leader's behavior (rather than followers' attributions) such as fostering 
collective identities or serving as role models (e.g., "... emphasizes the importance of having a collective sense of mission”). Inspirational motivation was measured with four items that described leader's behaviors such as challenging followers with high standards or communicating optimism about future goal attainment (e.g., ". . a articulates a compelling vision of the future”). Unit leaders' charismatic leader behaviors were rated by the superior to whom the unit leaders reported using a fivepoint Likert scale ranging from 1 for "never" to 5 for "always."

Finally, we used education and rank as individuallevel control variables. We originally collected education information through a multiple-choice question with seven categories ranging from 1 for "less than 8th grade" to 7 for "graduate degree." Responses predominantly fell into two of the seven categories, "high school graduate or G.E.D." (54.5\%) and "some college" $(35.8 \%)$. Thus, we recoded education into a dichotomous variable with 0 for "high school diploma or less" (60\%) and 1 for "some college and above" $(40 \%)$. We believe this dichotomization is meaningful since college education brings individual Marines additional responsibilities and opportunities. In addition, rank information was collected and coded as an ordinal variable with four ranks (PFC, LCPL, CPL, and SGT). Although these four ranks are lower-level positions within the Marine Corps, job demands may vary across rank with higher ranks having additional responsibilities and opportunities.

Analytical approach. We used SPSS 17.0 for analyzing descriptive statistics and HLM 6.06 (hierarchical linear modeling; Raudenbush \& Bryk, 2002) for multilevel models. In order to appropriately test and interpret multilevel estimates as well as to alleviate potential level-2 estimation problems due to multicollinearity (Hofmann \& Gavin, 1998), we centered the Level 1 predictors (stressors and appraisals) at unit means (i.e., group-mean centering) and centered the Level 2 predictor (charismatic leadership) at sample means (i.e., grand-mean centering). Specifically, according to Hofmann and Gavin (1998), we group-centered the Level 1 predictors so that the level-1 intercept variance was equal to the between-group variance in the outcome. As a result, the Level 2 regression coefficients simply represent the group-level relationship between Level 2 predictors and the outcome. The use of groupcentering makes it easier to test and interpret the multilevel estimates, and is recommended for models with cross-level interactions (Hofmann \& Gavin, 1998). We grand-mean centered the Level 2 predictor to avoid high correlations between the intercept and slope estimates across groups, which can help to alleviate potential level-2 estimation problems due to multicollinearity (Hofmann \& Gavin, 1998).

\section{Results}

Table 1 summarizes the descriptive statistics, internal consistency reliabilities, and zero-order correlations of the study variables. The challenge stressor mean is above the range of previous studies and the hindrance stressor mean is comparable to that found in other studies (Cavanaugh et al., 2000; LePine et al., 2004; Rodell \& Judge, 2009; Zhang et al., 2014).

Hypotheses tests. We adopted Muller, Judd, and Yzerbyt's (2005) procedures for testing moderated mediation and specified a two-level dual-stage

TABLE 1

Study 1: Means, Standard Deviations, and Intercorrelations among Study Variables

\begin{tabular}{|c|c|c|c|c|c|c|c|c|c|c|}
\hline Variables & Mean & $S D$ & $\alpha$ & 1 & 2 & 3 & 4 & 5 & 6 & 7 \\
\hline \multicolumn{11}{|l|}{ Individual-Level Variables } \\
\hline 1. Challenge Stressors & 3.40 & 0.65 & .90 & - & & & & & & \\
\hline 2. Hindrance Stressors & 2.54 & 0.79 & .93 & $.33^{*}$ & - & & & & & \\
\hline 3. Challenge Appraisals & 3.31 & 0.85 & .83 & $.31^{*}$ & $-.26^{*}$ & - & & & & \\
\hline 4. Hindrance Appraisals & 2.78 & 0.75 & .70 & .05 & $.50 *$ & $-.36^{*}$ & - & & & \\
\hline 5. Task Performance & 4.02 & 0.80 & .90 & .04 & -.05 & -.05 & -.16 & - & & \\
\hline 6. Education & 0.40 & 0.49 & - & .09 & $.27^{*}$ & -.16 & .09 & .12 & - & \\
\hline 7. Rank & 2.18 & 0.74 & - & .03 & .12 & -.14 & .06 & $.26^{*}$ & .12 & 一 \\
\hline \multicolumn{11}{|l|}{ Unit-Level Variables } \\
\hline 8. Charismatic Leadership & 3.49 & 0.70 & .89 & & & & & & & \\
\hline
\end{tabular}

Note: $N=149$ enlisted Marines ( $N=74$ for task performance) and 33 unit leaders.

${ }^{*} p<.05$ 
moderated mediation model (Liu, Zhang, \& Wang, 2012). Our models were complicated because we hypothesized two moderated mediation effects (challenge and hindrance). Although a more unified test of this model, using the multilevel structural equation modeling approach (MSEM; Liu et al., 2012; Preacher, Zyphur, \& Zhang, 2010), could potentially provide a more definitive set of results with regard to the complete model, our limited sample size necessitates this generally accepted, but admittedly more piecemeal, approach. We tested our hypotheses with four hierarchical linear models. Model 1 allows the overall effects of challenge and hindrance stressors on task performance to be moderated by charismatic leadership. Model 2 allows effects of challenge stressors on challenge appraisals to be moderated by charismatic leadership. Model 3 allows effects of hindrance stressors on hindrance appraisals to be moderated by charismatic leadership. Model 4 allows the mediators' (challenge and hindrance appraisals) partial effects on task performance to be moderated by charismatic leadership. Although not the focus of this study, moderations of cross-links (the links between challenge stressors and hindrance appraisals, and between hindrance stressors and challenge appraisals) were estimated and controlled. Rank and education were included as exogenous control variables for all models. Results of the above four models are summarized in Table 2 and Figure 1.

Mediation effects through cognitive appraisals. As shown in Table 2, results of Model 2 suggest that challenge stressors have a positive effect on challenge appraisals $(\gamma=.45, p<.05)$ whereas results of Model 4 indicate no significant relationship between challenge appraisals and task performance $(\beta=-.03, p>$.05). To examine indirect effects through cognitive appraisals, which speak to Hypotheses $1 \mathrm{a}$ and $1 \mathrm{~b}$, we calculated compound coefficients that are not normally distributed (Edwards \& Lambert, 2007). Because the traditional resampling method (e.g., bootstrapping) cannot be applied to multilevel models, we adopted a Monte Carlo approach of resampling to construct biascorrected confidence intervals for the indirect effects (Liu et al., 2012; Seligman \& Preacher, 2008). The indirect effect of challenge stressors on performance through challenge appraisals is not significant ( $\rho=-.01, p>.05)$. Although Hypothesis 1a is not supported, we note that a significant mediation effect is not statistically required for the test of moderated mediation (Liu et al., 2012). For hindrance appraisals, results of Model 3 suggest that hindrance stressors have a positive effect on hindrance appraisals $(\gamma=.41, p<.05)$, and results of Model 4 suggest that hindrance appraisals have a negative effect on task performance $(\beta=-.81$, $p<.05)$. The overall indirect effect of hindrance stressors on task performance via hindrance appraisals is significantly negative $(\rho=-.33, p<.05)$, which supports Hypothesis $1 \mathrm{~b}$.

Moderation of the appraisal process. The appraisal process is the first stage of the mediation in which we hypothesized that the effects of stressors on appraisals will depend on unit-level charismatic leadership (Hypotheses 2a and 2b). Results

TABLE 2

Study 1: HLM Results for Challenge Appraisals, Hindrance Appraisals, and Task Performance

\begin{tabular}{|c|c|c|c|c|}
\hline \multirow[b]{2}{*}{ Predictors } & \multicolumn{4}{|c|}{ Endogenous Variables } \\
\hline & $\begin{array}{c}\text { Task Performance } \\
\text { (Model 1) }\end{array}$ & $\begin{array}{c}\text { Challenge } \\
\text { Appraisals (Model 2) }\end{array}$ & $\begin{array}{c}\text { Hindrance } \\
\text { Appraisals (Model 3) }\end{array}$ & $\begin{array}{c}\text { Task Performance } \\
\text { (Model 4) }\end{array}$ \\
\hline Challenge Stressors & .20 & $.45^{*}$ & .08 & $.19^{*}$ \\
\hline Hindrance Stressors & $-.25^{*}$ & $-.40^{*}$ & $.41^{*}$ & .10 \\
\hline Challenge Appraisals & & & & -.03 \\
\hline Hindrance Appraisals & & & & $-.81^{*}$ \\
\hline Charismatic Leadership (CL) & .16 & .27 & $-.51^{*}$ & .19 \\
\hline Challenge Stressors $\times$ CL & $.32^{*}$ & $.29 *$ & -.14 & .10 \\
\hline Hindrance Stressors × CL & .19 & -.24 & .04 & .01 \\
\hline Challenge Appraisals × CL & & & & $.34^{*}$ \\
\hline Hindrance Appraisals × CL & & & & $.54^{*}$ \\
\hline Rank & .22 & -.12 & .06 & $.34^{*}$ \\
\hline Education & .06 & $-.27^{*}$ & .11 & .04 \\
\hline
\end{tabular}

Note: Individual level, $n=74$. Unit level, $n=33$. Standardized path coefficients.

${ }^{*} p<.05$ 
FIGURE 1

\section{Summary of Hypotheses (H1-H3) and Model Results}

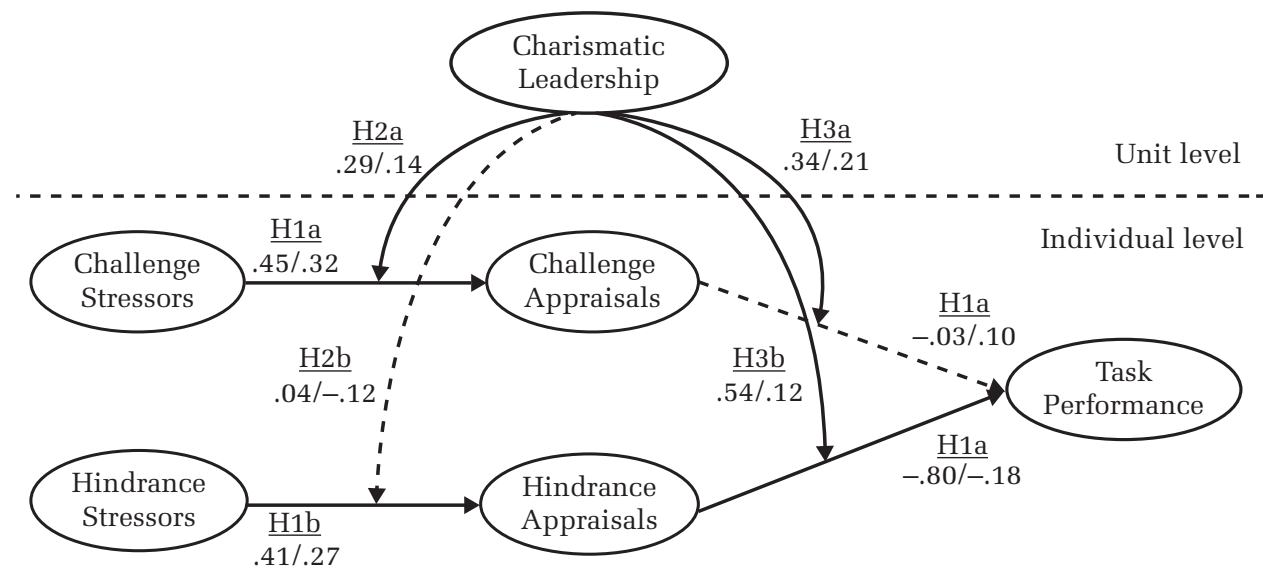

Note: Estimates left of each slash are standardized results obtained from separate multilevel regression equations that predicted challenge appraisals, hindrance appraisals, and task performance in Study 1. Estimates right of each slash are standardized path coefficients from the structural equation model that simultaneously predicts challenge appraisals, hindrance appraisals, and task performance in Study 2. Dashed line indicates $p>.05$.

of Model 2 suggest that the positive effect of challenge stressors on challenge appraisals $(\gamma=.45$, $p<.05)$ is moderated by charismatic leadership $(\gamma=.29, p<.05)$. Simple slopes, plotted in the left panel of Figure 2, indicate that, for those whose unit leaders are more charismatic, challenge stressors are more positively related to challenge appraisals $(\gamma=.75, p<.05)$ than for those whose unit leaders are less charismatic $(\gamma=.16, p>.05)$. Therefore, Hypothesis 2a is supported. The relationship between hindrance stressors and hindrance appraisals $(\gamma=.41, p<.05)$, contrary to our expectations, is not moderated by charismatic leadership $(\gamma=.04, p>.05)$. Hence, Hypothesis $2 \mathrm{~b}$ is not supported.

Moderation of the reaction process. The reaction process is the second stage of the mediation in which we hypothesized that the effects of appraisals on performance will depend on unit-level charismatic leadership (Hypotheses 3a and 3b). As

FIGURE 2

Plot of the Challenge Stressors $\times$ Charismatic Leadership Interaction on Challenge Appraisals for Study 1 (left) and Study 2 (right)
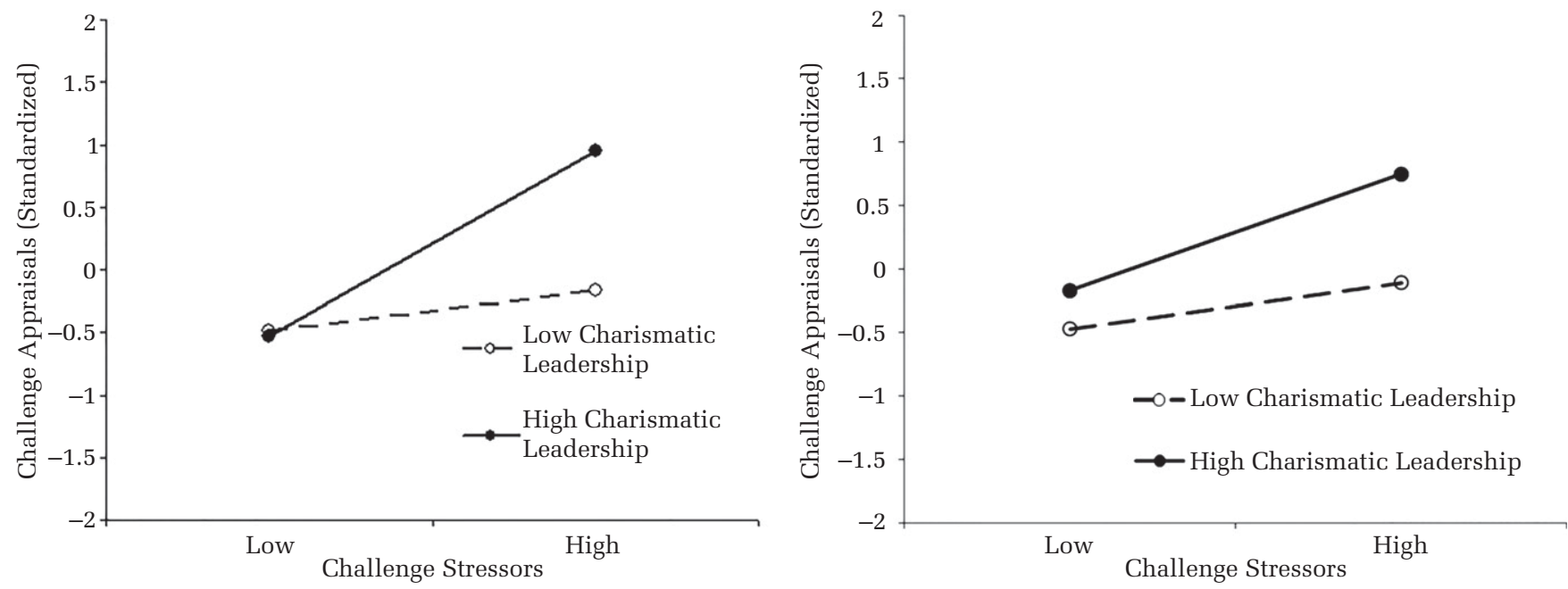
shown in Table 2, results of Model 4 suggest that charismatic leadership significantly moderates the effect of challenge appraisals on task performance $(\gamma=.34, p<.05)$, although the direct effect is not significant $(\gamma=-.03, p>.05)$. Simple slopes, plotted in the left panel of Figure 3, indicate that, for those whose unit leaders are more charismatic, challenge appraisals are more positively correlated with task performance $(\gamma=.31, p<.05)$ than for those whose unit leaders are less charismatic $(\gamma=-.37, p<.05)$. Therefore, Hypothesis 3a is supported, although, somewhat unexpectedly, the slope between challenge appraisals and task performance is negative when charismatic leadership is low.

Results of Model 4 suggest that hindrance appraisals have a significant negative effect on task performance $(\gamma=-.81, p<.05)$, and this effect is moderated by charismatic leadership $(\gamma=.54$, $p<.05$ ). Simple slopes, plotted in the left panel of Figure 4, indicate that, for those whose unit leaders are more charismatic, hindrance appraisals are less negatively correlated with task performance $(\gamma=-.26, p>.05)$ than for those whose unit leaders are less charismatic $(\gamma=-1.34, p<.05)$. Therefore, Hypothesis $3 \mathrm{~b}$ is supported; however, we note that the highest level of task performance occurs when low levels of charismatic leadership combined with low levels of hindrance appraisals, which was somewhat unexpected.
Moderated mediation effects. Taking the product of simple effects at high or low values (one standard deviation above or below the mean) of charismatic leadership, we calculated the conditional indirect effects for testing moderated mediation and used the Monte Carlo approach of resampling to construct bias-corrected confidence intervals (Seligman \& Preacher, 2008). For challenge appraisals, the overall indirect effect of challenge stressors on task performance is positive $(\rho=.23, p<.05)$ when charismatic leadership is high, and not significant $(\rho=-.06, p>.05)$ when charismatic leadership is low, which supports Hypothesis 4a. For hindrance appraisals, the overall indirect effect of hindrance stressors is not significant ( $\rho=-.11, p>.05$ ) when charismatic leadership is high and negative $(\rho=$ $-.97, p<.05)$ when charismatic leadership is low, which supports Hypothesis 4b. Although Muller et al. (2005) did not specify ways to determine the significance of the difference between conditional indirect effects, the pattern of our results in general supports hypotheses of our moderated mediation effects.

Study 1: Summary. The results of Study 1 reveal that charismatic leadership is associated with a positive relationship between challenge stressors and challenge appraisals (e.g., followers with a more charismatic leader are more likely to appraise challenges as promoting achievement and growth), and, in addition, a positive relationship between

FIGURE 3

Plot of the Challenge Appraisals $\times$ Charismatic Leadership Interaction on Task Performance for Study 1 (left) and Study 2 (right)
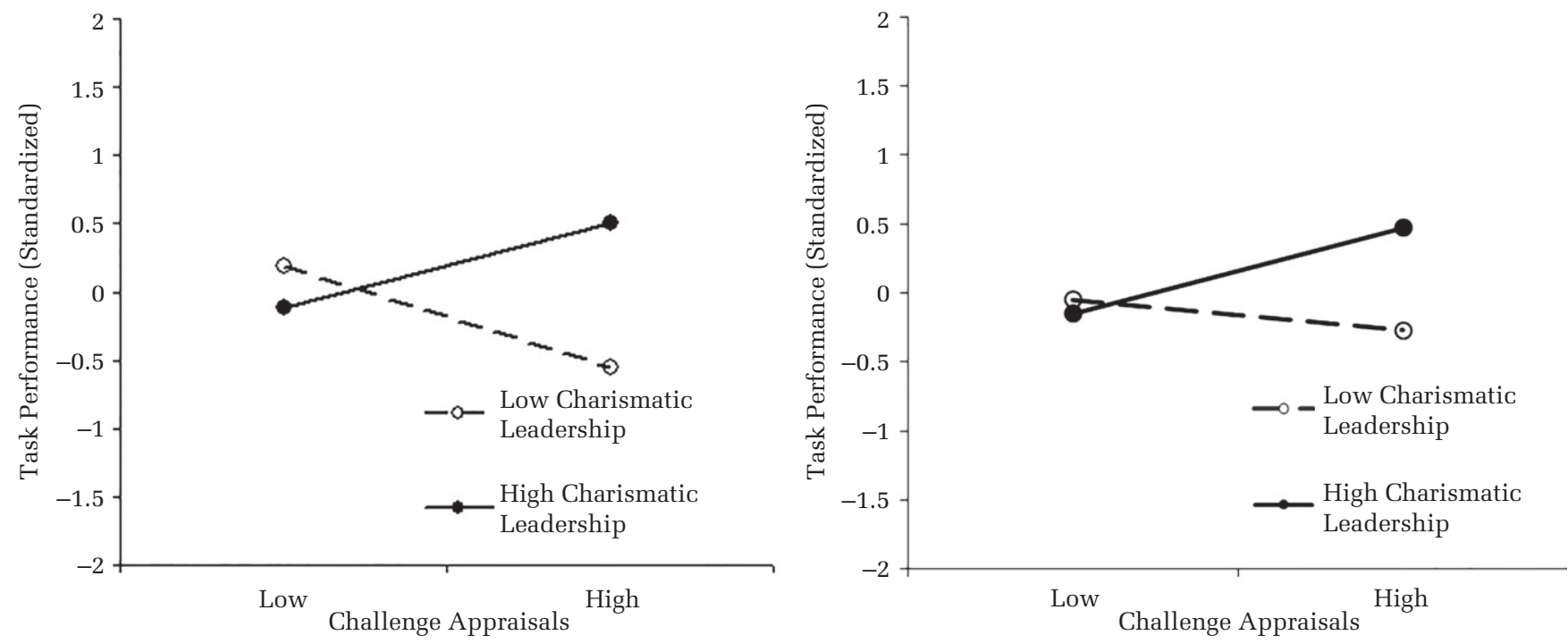
FIGURE 4

Plot of the Hindrance Appraisals × Charismatic Leadership Interaction on Task Performance for Study 1 (left) and Study 2 (right)

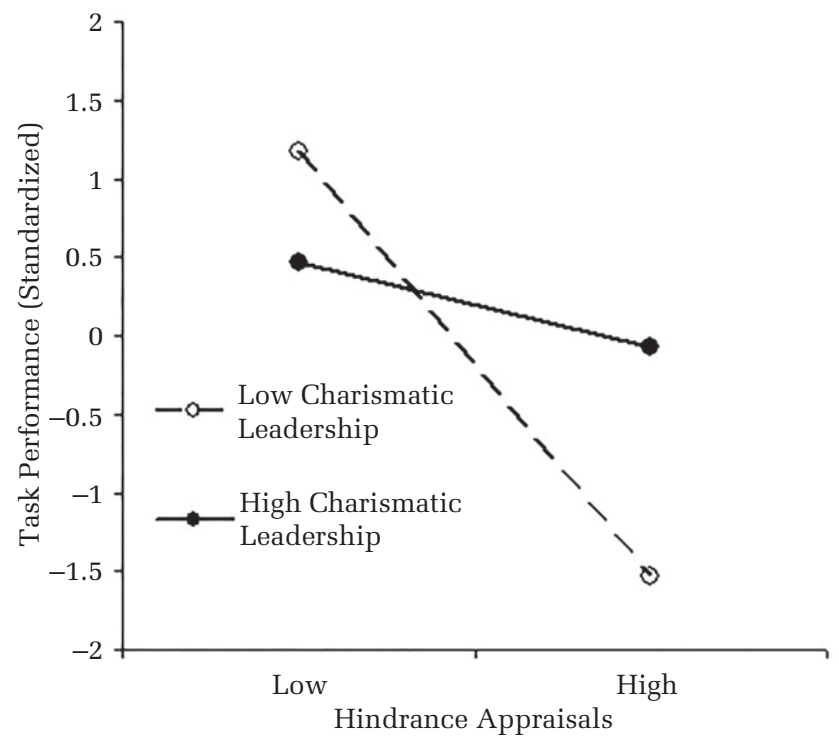

challenge appraisals and performance (e.g., followers with a more charismatic leader are more likely to transform the challenge appraisals into improved task performance). Conversely, our results reveal that, although charismatic leadership is not associated with a decrease in followers' appraisals of hindrance stressors (e.g., followers with a more charismatic leader are not less likely to appraise hindrances as threats to work achievements), charismatic leadership did prevent the hindrance appraisals from negatively impacting performance (e.g., followers with a more charismatic leader are less likely to transform the hindrance appraisals into decreased task performance).

There are, however, several features of Study 1 that limit confidence in our findings. First, although we feel our research design with respect to the measurement of leader charisma is novel and has potential strengths, it is also unconventional and has limitations. Specifically, whereas leadership scholars have predominantly focused on perceptions of followers, we measured charismatic leadership from the perspective of the leader's leader. Our thinking was that this design would result in ratings of leader behavior that would be more objective (in the sense that the leader's leader is a third party who is accountable for rating the leader's behavior), and that, because objective behavior is filtered through the cognitive frames of the followers to influence

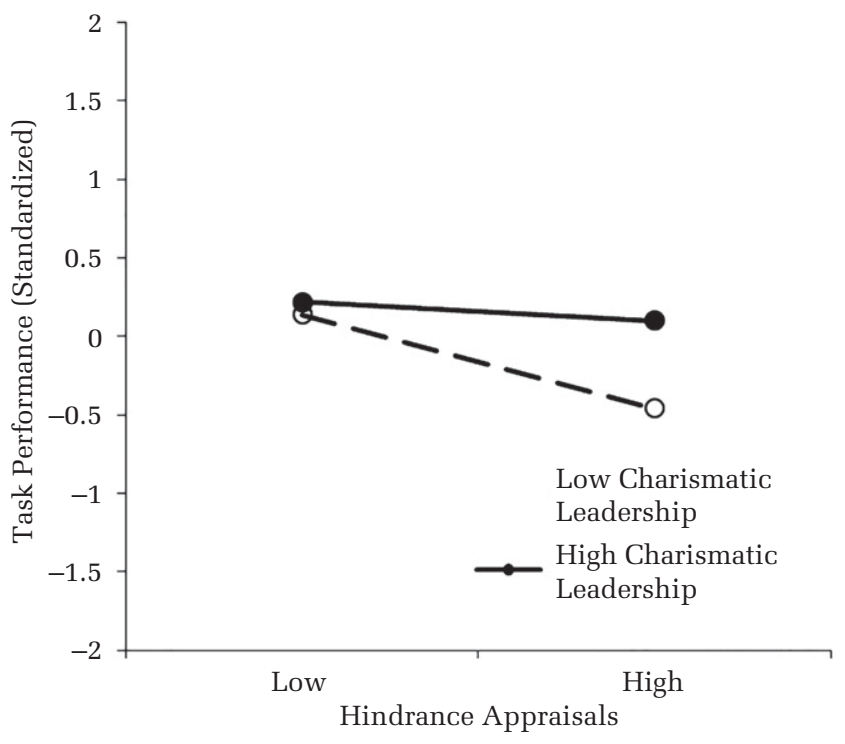

their behavior, our tests would be more conservative. However, we recognize that perceptions of the leaders' leaders are likely no more objective than perceptions of the followers, and, moreover, our design makes it difficult to know for sure that the Marine appraisal process is influenced by their perceptions of leader behavior, rather than something else. Second, the modesty of our sample size is not amenable to state-of-the-art approaches to testing moderated mediation. A larger sample size would make feasible a more integrative approach to our analyses, which would allow for greater confidence in our findings. Finally, there are features of our study that, if replicated, would greatly bolster confidence in our findings. Most important, perhaps, interactions are notoriously difficult to replicate, and, thus, if the same interaction patterns emerge in a new sample, greater certainty can be placed on the inferences we draw. In addition, replication would allow us to cross-validate our measures, especially our new appraisal measures.

\section{Study 2}

With these issues in mind, we collected data from another cohort of U.S. Marines to test our hypotheses. Although generalizability would have been enhanced had we used a completely different research setting, this follow-up study incorporates 
a different approach to measuring charismatic leader behaviors, and a change in the research setting would have made it impossible to reconcile differences in findings that are likely to occur in these types of replications. That is, we would not be able to answer the question of whether differences in our findings are due to differences in the nature of our sample or differences in the way we measured charismatic leader behaviors. Given that external validity is best addressed in studies of many samples conducted in different settings and time periods, we feel that the priority we place on internal validity is appropriate.

Sample and procedure. We collected data from five different ranks within the U.S. Marine Corps. Although the number of enlisted Marines we surveyed was higher in the second study $(n=270)$, they were demographically similar with the previous study. Again, participants were predominantly male $(81.8 \%)$, on average were 21.62 years old $(S D=2.74)$, and less than half $(37.5 \%)$ attended college. On average, the Marines had been enlisted for 28.88 months $(S D=21.65)$ and had been in their current ranks for 10.4 months $(S D=10.77)$. The breakdown of the ranks was similar to that in the first study: Private (PVT), 1\%; PFC, 22\%; LCPL, 40\% ; CPL, 28\%; and SGT, $9 \%$. In addition to the questions asked of the Marines in Study 1, we also asked them to rate their direct supervisor's charismatic leadership. The Marines were assured that their responses would be kept strictly confidential, and, in particular, no one in the Marine Corps would ever see how they rated their leader, or their responses to any other question for that matter. To reduce the problems with sample attrition, we decreased the time lag between the initial data collection from the Marines and the collection of task performance ratings from the Marines' direct superiors (from approximately three months to around three weeks). The benefit of this change is that we obtained matched ratings from 92 unit leaders for all 270 Marines.

Measures. We measured charismatic leadership, challenge stressors, hindrance stressors, challenge appraisals, hindrance appraisals, and task performance with the same items we used in Study 1. With regard to control variables, we included and coded individual Marine's rank and education in similar ways as Study 1 (one additional rank, "Private," was included in creating the ordinal rank variable), and also included measures of negative and positive affect (10 items each from the PANAS scales; Watson, Clark, \& Tellegen, 1988). Although several other dispositional constructs could have been used in this regard, affect is generally regarded as the most plausible alternative explanation for the relations among stress-related constructs and job performance. We specified a confirmatory factor analysis with eight factors as a check on the validity of the measures mentioned above (in italic). Results indicate that the model fit the data well $\left(\chi^{2}[1567]=\right.$ 3429.48 , CFI $=.90$, RMSEA $=.07$, SRMR $=.07)$. We also tested two alternative measurement models. One is a six-factor model with the challenge stressors and appraisals items loading on one factor and the hindrance stressors and appraisals items loading on another $\left(\chi^{2}[1569]=3812.13, \mathrm{CFI}=.88\right.$, $\mathrm{RMSEA}=.08$, SRMR $=.08)$. The other is a six-factor model with all stressors items (challenges and hindrances) loading on one factor and all appraisals items loading on another $\left(\chi^{2}[1569]=4366.15\right.$, CFI $=.86$, RMSEA $=.10$, SRMR $=.10)$. Model comparison results support both the differentiation between stressors and appraisals $\left(\Delta \chi^{2}[2]=382.65, p<.05\right)$ and the differentiation between challenges and hindrances $\left(\Delta \chi^{2}[2]=936.67, p<.05\right)$.

We specified a multigroup confirmatory factor analysis as a cross validation of our measurement of challenge and hindrance appraisals for Studies 1 and 2. Following the procedures suggested by Muthén and Muthén (1998-2012), we analyzed a baseline model with no constraints $\left(\chi^{2}=37.82, d f=16\right)$, a metric invariance model with all factor loadings held equal across two samples $\left(\chi^{2}=42.97, d f=22\right)$, and a scalar invariance model with all factor loadings and intercepts held equal across two samples $\left(\chi^{2}=\right.$ 47.08, $d f=26)$. Results suggest that factor loadings $\left(\Delta \chi^{2}[6]=5.15, p>.05\right)$ and intercepts $\left(\Delta \chi^{2}[4]=4.11\right.$, $p>.05)$ are equivalent in the factor models, so comparisons that are made on challenge and hindrance appraisals are valid across Study 1 and Study 2.

Analytical approach. We calculated the intraclass correlation for performance (ICC(1) $=.40, \chi^{2}$ $[87]=247.90, p<.05$ ), which indicated the necessity of partitioning its variance at both individual and unit levels. Again, performance ratings were not normally distributed (skewness $=-1.11, S E=.15$; kurtosis $=2.60, S E=.30$ ), so we transformed them $(\lambda=2)$ to bring skewness and kurtosis within the range of -1.0 and 1.0.

Using Mplus 6.11 (Muthén \& Muthén, 2010), we modeled the structural associations among study variables using the integrated approach outlined by Edwards and Lambert (2007), and tested all the proposed relationships simultaneously in an MSEM (Preacher et al., 2010). In comparison to the 
piecemeal approach of Study 1, this integrated approach does not require multiple stages of analysis and generates estimates that are less biased (Edwards \& Lambert, 2007; Liu et al., 2012). For each construct measured with multiple items, we used the average item score as a composite to represent the construct so that the overall model did not become overly complex. We modeled negative and positive affect as alternative mediators of the stressor-performance relationships and allowed them to covary with cognitive appraisals. The value of intraclass correlation $\left(\operatorname{ICC}(1)=.19, \chi^{2}[87]=149.58, p<.05\right)$ supports our conceptualization and operationalization of charismatic leadership as a unit-level moderator. Similar with Study 1, we centered the individual-level exogenous variables at each unit's mean value and the unit-level exogenous variable at the overall mean value.

\section{Results}

Table 3 summarizes the descriptive statistics, internal consistency reliabilities, and zero-order correlations of variables in Study 2. The challenge and hindrance stressor means are at the higher end of the range of previous studies (Cavanaugh et al., 2000; LePine et al., 2004; Rodell \& Judge, 2009; Zhang et al., 2014). We excluded rank and education from subsequent analyses because they are not related to any of the endogenous variables.

Hypothesis tests. Our hypotheses imply a twolevel dual-stage moderated mediation model (Edwards \& Lambert, 2007; Liu et al., 2012). A dualstage moderated mediation is present when the indirect (mediated) effect varies as a function of a moderator that strengthens or weakens the relationship between an independent variable and a mediator as well as the relationship between a mediator and an outcome variable (Liu et al., 2012). In our study, the key to testing moderated mediation is to examine whether the indirect effects of work stressors on performance through cognitive appraisals vary as a function of charismatic leadership, as well as to explain such variation in indirect effects based on the first-stage and second-stage moderations. Although we proposed mediation hypotheses in line with our theory, they are not statistically required for testing moderated mediation (Liu et al., 2012). We summarize the findings with the multilevel structural equation model that speaks to our hypotheses in Table 4 and Figure 1.

Mediation effects through cognitive appraisals. As illustrated in Table 4 and Figure 1, challenge appraisals are positively related to challenge stressors $(\gamma=.32, p<.05)$ but are not related to task performance $(\beta=.10, p>.05)$. We adopted the Monte Carlo approach of resampling to construct biascorrected confidence intervals for the indirect effects (Liu et al., 2012; Seligman \& Preacher, 2008). As shown in Table 5 , the indirect effect of challenge stressors on task performance via challenge appraisals is not significant $(\rho=.03 ; p>.05)$. Hence, Hypothesis 1a is not supported. However, we note that this average indirect effect may be nonsignificant due to the existence of moderators that we examine in the next section. Also, as illustrated in Table 4 and Figure 1, hindrance appraisals are

TABLE 3

Study 2: Means, Standard Deviations, and Intercorrelations among Study Variables

\begin{tabular}{|c|c|c|c|c|c|c|c|c|c|c|c|c|}
\hline Variables & Mean & $S D$ & $\alpha$ & 1 & 2 & 3 & 4 & 5 & 6 & 7 & 8 & 9 \\
\hline \multicolumn{13}{|l|}{ Individual-Level Variables } \\
\hline 1. Challenge Stressors & 3.62 & 0.72 & .91 & - & & & & & & & & \\
\hline 2. Hindrance Stressors & 2.71 & 0.75 & .88 & $.28 *$ & - & & & & & & & \\
\hline 3. Challenge Appraisals & 3.24 & 0.81 & .83 & $.32 *$ & $-.15^{*}$ & - & & & & & & \\
\hline 4. Hindrance Appraisals & 2.86 & 0.64 & .74 & $.14^{*}$ & $.29^{*}$ & .03 & - & & & & & \\
\hline 5. Negative Affect & 1.83 & 0.73 & .92 & .06 & $.28^{*}$ & $-.22 *$ & $.20^{*}$ & - & & & & \\
\hline 6. Positive Affect & 3.57 & 0.86 & .95 & $.24 *$ & $-.19 *$ & .41 * & .06 & $-.20^{*}$ & - & & & \\
\hline 7. Task Performance & 4.12 & 0.54 & .80 & .09 & .01 & .15 & $-.14^{*}$ & -.11 & .09 & - & & \\
\hline 8. Education & 0.36 & 0.48 & - & .10 & .02 & -.08 & .03 & .02 & -.07 & -.02 & - & \\
\hline 9. Rank & 3.21 & 0.92 & - & $.26^{*}$ & $.32^{*}$ & -.05 & .03 & .02 & -.05 & -.01 & $.14^{*}$ & - \\
\hline \multicolumn{13}{|l|}{ Unit-Level Variables } \\
\hline 10. Charismatic Leadership & 3.99 & 0.54 & .93 & & & & & & & & & \\
\hline
\end{tabular}

Note: $N=270$ enlisted Marines and 92 unit leaders.

${ }^{*} p<.05$ 
TABLE 4

Study 2: MSEM Results for Challenge Appraisals, Hindrance Appraisals, and Task Performance

\begin{tabular}{lccc}
\hline & \multicolumn{3}{c}{ Endogenous Variables } \\
\cline { 2 - 4 } \multicolumn{1}{c}{ Predictors } & $\begin{array}{c}\text { Challenge } \\
\text { Appraisals }\end{array}$ & $\begin{array}{c}\text { Hindrance } \\
\text { Appraisals }\end{array}$ & $\begin{array}{c}\text { Task } \\
\text { Performance }\end{array}$ \\
\hline Challenge Stressors & $.32^{*}$ & -.01 & .14 \\
Hindrance Stressors & $-.16^{*}$ & $.27^{*}$ & .08 \\
Challenge Appraisals & & & .10 \\
Hindrance Appraisals & & & $-.18^{*}$ \\
Charismatic & $.29^{*}$ & -.05 & .16 \\
$\quad$ Leadership (CL) & & & .00 \\
Challenge & $.14^{*}$ & .00 & .08 \\
$\quad$ Stressors $\times$ CL & & & .07 \\
Hindrance & -.02 & & $.21^{*}$ \\
$\quad$ Stressors $\times$ CL & & & $.12 *$ \\
Challenge & & & -.07 \\
$\quad$ Appraisals $\times$ CL & & & -.01 \\
Hindrance & & & \\
$\quad$ Appraisals $\times$ CL & & & \\
Negative Affect & & & \\
Positive Affect & & & \\
\hline
\end{tabular}

Note: Standardized path coefficients.

${ }^{*} p<.05$

positively related to hindrance stressors $(\gamma=.27$, $p<.05$ ) and negatively related to task performance $(\beta=-.18, p<.05)$. As shown in Table 5 , the indirect effect of hindrance stressors on task performance via hindrance appraisals is significantly negative $(\rho=$ $-.05 ; p<.05)$. As such, Hypothesis $1 \mathrm{~b}$ is supported.

TABLE 5

Study 2: Summary of the Indirect Effects of Work Stressors on Task Performance via Stressor Appraisals

\begin{tabular}{lcc}
\hline Indirect Effects & $\begin{array}{c}\text { Challenge } \\
\text { Stressors }\end{array}$ & $\begin{array}{c}\text { Hindrance } \\
\text { Stressors }\end{array}$ \\
\hline $\begin{array}{l}\text { Via Challenge Appraisals } \\
\text { Average indirect } \\
\text { effects }\end{array}$ & .03 & -.00 \\
Charismatic leadership & & \\
$\quad$ High & $.14^{*}$ & -.00 \\
$\quad$ Low & -.02 & .00 \\
$\quad$ Difference & $.16^{*}$ & -.00 \\
Via Hindrance Appraisals & & $-.05^{*}$ \\
Average indirect \\
effects
\end{tabular}

Note: Estimates were tested for significance using bias-corrected confidence intervals from 2,000 bootstrap resamples.

${ }^{*} p<.05$
Moderation of the appraisal process. The moderating effects of charismatic leadership over the stressor-appraisal linkages (i.e., the appraisal process) are summarized in Table 4 and Figure 1. Specifically, charismatic leadership moderates the linkage between challenge stressors and challenge appraisals $(\gamma=.14, p<.05)$. The nature of this interaction is illustrated in the right panel of Figure 2, which shows that, for Marines whose unit leaders score high on charismatic leadership, challenge stressors are more positively related to challenge appraisals ( $\beta=.46, p<.05$ ) than for Marines whose unit leaders score low on charismatic leadership $(\beta=.18, p<.05)$. As such, Hypothesis 2 a is supported. Charismatic leadership, however, does not moderate the linkage between hindrance stressors and hindrance appraisals $(\gamma=-.12, p>.05)$, and thus Hypothesis $2 \mathrm{~b}$ is not supported.

Moderation of the reaction process. The moderating effects of charismatic leadership over the appraisal-performance linkages (i.e., the reaction process) are also shown in Table 4 and Figure 1. Charismatic leadership moderates the linkage between challenge appraisals and task performance $(\gamma=.21, p<.05)$. This interaction is illustrated in the right panel of Figure 3. Specifically, for Marines whose unit leaders score high on charismatic leadership, challenge appraisals are more positively related to task performance $(\beta=.31, p<.05)$ than for Marines whose unit leaders score low on charismatic leadership $(\beta=-.11, p>$.05). Hence, Hypothesis 3a is supported.

Charismatic leadership also moderates the linkage between hindrance appraisals and task performance $(\gamma=.12, p<.05)$. This interaction is illustrated in the right panel of Figure 4. For Marines whose unit leaders score high on charismatic leadership, hindrance appraisals are less negatively related to task performance $(\beta=-.06, p>.05)$ than for Marines whose unit leaders score low on charismatic leadership ( $\beta=-.30, p<.05)$. Hence, Hypothesis $3 b$ is also supported.

Moderated mediation effects. Moderated mediation suggests that the indirect effect that is attributed to the mediator varies at different levels of the moderator. We again adopted the Monte Carlo approach to construct bias-corrected 95\% confidence intervals for indirect effects of stressors on performance via appraisals at "high" and "low" levels (one standard deviation above and below the average) of charismatic leadership, as well as the difference between these two conditional indirect effects (Liu et al., 2012; Seligman \& Preacher, 2008). As 
summarized in Table 5, the indirect effect of challenge stressors on task performance via challenge appraisals differ significantly $(\Delta \rho=.16 ; p<.05)$ when charismatic leadership is at high $(\rho=.14$; $p<.05)$ versus low levels $(\rho=-.02 ; p>.05)$. Hence, the indirect effect of challenge stressors on task performance via challenge appraisals is moderated by charismatic leadership, which supports Hypothesis 4a. The indirect effect of hindrance stressors on task performance via hindrance appraisals also differs significantly $(\Delta \rho=-.11 ; p<.05)$ when charismatic leadership is at high $(\rho=-.01 ; p>.05)$ versus low levels $(\rho=-.11 ; p<.05)$. As such, Hypothesis $4 \mathrm{~b}$ is supported.

Study 2: Summary. Our findings in Study 2 are highly consistent with findings in Study 1 . The fact that results were cross-validated across two studies with distinct features in design (controlling for positive and negative affect and examining leadership as observed by followers) and analytical procedures bolsters our confidence in interpreting our findings. Study 2 not only offers more direct evidence of moderated mediation but also less biased estimates.

\section{OVERALL DISCUSSION}

We developed and tested a theoretical model to examine whether and how unit-level leaders' charismatic behaviors impact the effects of work stressors on followers' task performance. Using the transactional theory of stress, we extended the challengehindrance stressor framework by proposing that charismatic leaders increase the positive effect of challenge stressors and buffer the detrimental effect of hindrance stressors on performance. They amplify the tendency of followers to see the positive side of challenge stressors, consequently increasing the positive outcomes, and influence followers to respond less negatively to hindrance stressors, consequently decreasing negative outcomes.

Across two studies, we found that challenge stressors were more positively associated with the performance of Marines whose leaders enact charismatic behaviors, as judged by either their leaders' superiors or themselves. These Marines appraised challenge stressors as being more challenging, and they were more likely to respond to this appraisal with higher performance. Also, across the two studies, we found that charismatic leader behaviors negated the strong negative effect of hindrance appraisals on job performance. However, contrary to our hypotheses, we found that charismatic leader behaviors did not influence how Marines appraised hindrance stressors. We offer three explanations for the unexpected finding. First, charismatic leaders, as purpose-driven role models, may be ineffective when managing the meaning of hindrance stressors from debilitating to enhancing, given the characteristically ambiguous, bureaucratic, and inefficient nature of the demands that may be less amenable to meaning management. Similarly, charismatic leaders may have more discretion in the messages they deliver and actions they take to manage the meaning of challenge stressors and less discretion for hindrance stressors (Crum et al., 2013), especially if the hindrance stressors need to be administratively managed or fairly adhered to (Scott, Garza, Conlon, \& Kim, 2014; Zhang et al., 2014). Third, it is possible that other leadership styles (e.g., transactional) may be more effective at buffering both the appraisal and the reaction process of hindrance stressors. Indeed, Zhang et al. (2014) found that transactional leadership moderated the relationship between hindrance stressors and justice perceptions, while transformational leadership did not.

\section{Theoretical Contributions}

The primary theoretical contribution of this research is that we embedded the stress process in a multilevel organizational context and introduced leadership as an important influence on this process through influencing how followers both appraise and respond to different stressors. The transactional theory of stress (Lazarus \& Folkman, 1984) does not distinguish between challenge and hindrance stressors and challenge-hindrance stressor research does not differentiate the primary and secondary appraisal process (Cavanaugh et al., 2000; LePine et al., 2004; Rodell \& Judge, 2009; Zhang et al., 2014). We examine both. Specifically, we built our model on the transactional theory of stress and the challengehindrance stressor framework and examined how leaders can alter the stress process and enhance follower performance through amplifying the positive potentials of challenge stressors through appraisals and reactions and alleviating the detrimental effects of hindrance stressors through reactions. We note that charismatic leadership was assessed by superiors in Study 1 and therefore considered a leader-level construct that is independent from follower' perceptions and attributions. Our findings of a characteristic level of charismatic leadership behavior that is observed relatively 
consistently by focal leaders' followers in Study 2 bolster this consideration. Our study opens up a new domain of potential group or organizational features (e.g., team interdependence, organizational culture, human resource practice, etc.) that may interact with stressful work conditions in determining employee performance.

We extend work stress research, and specifically the work of Lazarus and Folkman (1984) and the challenge-hindrance stressor framework, by examining cognitive appraisals as mediating mechanisms that link challenge and hindrance stressors to their unique performance consequences. Our results revealed that cognitive appraisals provided subtle and meaningful procedural explanations for the overall influence of charismatic leadership on either the appraisal process or the reaction process, or both. Our study extends the research of Wallace et al. (2009) and Zhang et al. (2014) by showing that the effects of contextual factors, such as charismatic leadership, on the relationship between hindrance stressors and performance are more complex that originally believed. While charismatic leadership did not influence how hindrance stressors were appraised, they negated the strong negative effect of hindrance appraisals on job performance.

Our research contributes to theories of leadership, especially charismatic leadership. While studies have reported direct correlations between transformational leadership and felt stress (Bono et al., 2007; Seltzer et al., 1989; Sosik \& Godshalk, 2000; see Skakon et al., 2010 for a review), no studies have specifically examined how charismatic leaders impact follower performance within the stress process. Our study extends research in this area by providing evidence that charismatic leadership is effective in increasing the positive effect of challenge stressors and buffering the negative effect of hindrance appraisals on task performance. We provide direct support for the need to examine contextual contingencies that may impact charismatic leadership emergence and effectiveness (Shamir \& Howell, 1999).

\section{Practical Implications}

Our study benefits stress management practice and leadership development in several ways. First, our findings enrich the content of stress management. Practitioners may learn from prior research that demands appraised as challenges or hindrances have differential effects on performance. Our research shows that these appraisals are not automatic and may depend on leaders' behaviors. For instance, employees who have a non-charismatic leader may find it difficult to appraise job demands such as workload or time pressure as challenges (Kickul \& Posig, 2001), and, even if employees appraise job demands in the commensurate way, the differential effects on performance are not guaranteed and may be dependent on their leader's charismatic behaviors. That is, the use of challenge stressors to motivate employees who have a noncharismatic leader may actually result in a decrease of performance (Courtright et al., 2014).

Second, our findings motivate the engagement of managers in stress management practices. Managers have not been well informed about what they can do to help employees manage their daily job demands and whether their efforts will lead to any valuable outcomes. Many might consider stress management solely as others' job responsibilities (e.g., human resources, employee assistance programs, counseling services, etc.). Our findings demonstrate that charismatic leaders not only help people thrive in the face of both challenge and hindrance stressors, they can influence how employees' appraise challenge stressors, and their effort can be rewarded with improved task performance, which is of central importance to the management of the organization. Charismatic leaders are able to manage the meaning of challenge stressors, capitalize on the motivating force of challenge appraisals, and mitigate the demotivating force of hindrance appraisals on performance. Organizations can therefore explicitly include the management of employees' stress as one of leader's responsibilities and reward the demonstration of charismatic leadership behaviors that lead to employee effectiveness. As our research shows, as charismatic leaders inspire, motivate, and communicate optimism and a vision for the future, they can have a significant effect on the well-being of their employees.

Third, our study can also benefit leadership development and training. Charismatic leadership behaviors such as role modeling, frame alignment, articulation of visions, and displaying conviction could be incorporated into training courses, especially for clients who are facing work stress-related productivity loss in their organizations. Experimental research involving bank branch managers suggests that these leadership behaviors can be learned (Barling, Weber, \& Kelloway, 1996). Our findings inform practitioners or update their prior knowledge in that charismatic leadership emerges 
and is effective at all levels of the organization. In addition, because charismatic leadership can be effectively rated by leaders' superiors, it is possible to incorporate charismatic behaviors into the criteria for internal promotions or team design.

\section{Limitations and Future Research}

We addressed internal validity issues by collecting data from three independent sources and allowing a three-month "temporal precedence" (Cook \& Campbell, 1979) between measurements of stressors and task performance in Study 1. In Study 2 , we collected data from two independent sources and allowed for a three-week "temporal precedence" to alleviate problems of attrition. We did, however, measure stressors and appraisals in both studies in the cross-sectional fashion. Although the proposed causal direction is explicitly implied by theory (Lazarus \& Folkman, 1984), alternative explanations for the observed relationships between stressors and appraisals may exist (Podsakoff, MacKenzie, Lee, \& Podsakoff, 2003). For example, an employee who perceives his or her job as challenging and potentially rewarding may be more aware of the challenge stressors, like task complexity or responsibilities, at work. Experimental or longitudinal research is needed to ascertain the causal nature of the stressor-appraisal relationship. For example, researchers may adopt an experience sampling approach that allows participants to evaluate stressors at work during the day and evaluate appraisals at the end of the day. Researchers may also consider including one or more marker variables that are theoretically irrelevant to study variables to estimate and adjust for the effect of common method variances (Lindell \& Whitney, 2001).

Individual characteristics may also account for alternative explanations. For example, people with some characteristics (e.g., high cognitive ability or high core self-evaluation) may both encounter more challenge stressors at work and appraise their work as challenging and rewarding. In Study 2, we controlled for affect to address this issue. An additional issue regarding the stressor-appraisal relationship is the cross-links between challenge stressors and hindrance appraisals or between hindrance stressors and challenge appraisals. We controlled for these links in the analyses, but did not include them in the hypotheses. According to Lazarus and Folkman (1984), a situation can be appraised as both challenging and hindering, and the relationship between challenge and hindrance appraisals can shift as an encounter unfolds (Webster et al., 2011). Future research could address the psychological mechanisms underlying such cross-links and identify individual- and group-level contingencies (e.g., do people with high levels of political skills perceive office politics more as challenges than hindrances?).

Another limitation of our study is that we did not include additional contextual factors that may be of importance. We assessed what we thought would be most important for examining the stress process and for ruling out alternative explanations (e.g., affect), but recognize that our model is incomplete. As survey length was a concern, we balanced feasibility with comprehensiveness. Future research should build on our findings by examining the role of other contextual and contingency factors (support, justice, other leadership styles) in the appraisal process. What we do not know is whether transformational leaders impact the stress appraisal process through perceptions of support, justice, or other contextual factors (Wallace et al., 2009; Zhang et al., 2014). We also do not know the impact of transactional leaders on the stress process. It is possible that transactional leaders manage the meaning of hindrance stressors more effectively than charismatic leaders, administratively or through their focus on distributive and procedural justice (Zhang et al., 2014).

Our sample is from a military setting and we focused on charismatic behaviors of unit leaders at the lower level of the Marine Corps who directly monitor employee performance. Future research may examine the external validity of our findings, especially the effectiveness of charismatic leadership, in multiple organizational settings, including business settings. Although factors relevant to a military setting (e.g., promotion practices) may have impacted our findings, we are optimistic about their generalizability. First, the military is considered a typical strong situation that is structured, clear, and mechanistic (Bell \& Staw, 1989). Given that charismatic leadership is more likely to emerge and is more effective in weak or dynamic situations rather than strong situations (Shamir \& Howell, 1999), we expect our findings to generalize to both contexts. Second, researchers have noted that leadership theories are applicable not only to business settings, but military and educational settings as well (Bass, 1998). Although we are optimistic about our study's generalizability both in terms of level and setting, it would be interesting to examine 
whether charismatic leaders at higher and lower levels of organizations rely on different sets of behaviors for influencing stressors or have more or less discretion over challenge and hindrance stressors that affects whether appraisals can be effectively managed.

Last, we chose to examine the role of charismatic leadership because it is the leadership style that is conceptually associated with stress management and significantly related to both employees' feelings of stress and strains and employees' performance. Future research may explore the effectiveness of other leadership styles in daily stress management, especially the management of hindrance stressors. For example, transformational leadership is effective in driving extraordinary performance (Bass, 1985). Two of the dimensions that are not categorized as charismatic may provide incremental contributions to our proposed model. "Intellectual stimulation" captures how leaders stimulate their followers to be innovative by questioning assumptions and approaching old situations in new ways. "Individual consideration" captures how leaders pay special attention to followers' needs for achievement and growth by acting as coach or mentor (Bass, 1985). Individual consideration as been shown to reduce burnout (Seltzer et al., 1989) and may have incremental moderation effects on the stressorperformance relationship in comparison to charismatic leadership (Rafferty \& Griffin, 2006). In addition, transactional leadership has been found to reduce the negative effect of hindrance stressors on job performance by weakening the link between the stressors and justice perceptions (Zhang et al. (2014), while the contingent rewards component contributes to employee performance in its unique way (Judge \& Piccolo, 2004) and has also been shown to reduce burnout (Seltzer et al., 1989). Incorporation of transactional leadership in our proposed model may evoke a new stream of explanations for the effectiveness of leadership on the stressor-performance relationship.

\section{CONCLUSION}

Our research extends the challenge stressorhindrance stressor framework by drawing attention to the importance of examining the primary appraisal process within the framework. Our results show that charismatic leaders not only influence followers' reactions to challenge and hindrance appraisals, but also influence the appraisal of challenge stressors as challenging. Specifically, Marines with leaders who enact more charismatic behaviors appraised challenge stressors as more challenging, and responded to that appraisal with higher performance. Although Marines with a more charismatic leader did not appraise hindrance stressors as less so, they responded to the hindrance appraisal with higher performance. In essence, we found that charismatic leaders turned their followers' stressor pain to performance gain.

\section{REFERENCES}

Antonakis, J., Avolio, B. J., \& Sivasubramaniam, N. 2003. Context and leadership: An examination of the ninefactor full-range leadership theory using the multifactor leadership questionnaire. The Leadership Quarterly, 14: 261-295.

Arnold, K. A., Turner, N., Barling, J., Kelloway, E. K., \& McKee, M. C. 2007. Transformational leadership and psychological well-being: The mediating role of meaningful work. Journal of Occupational Health Psychology, 12: 193-203.

Avolio, B. J. 2004. Examining the full range model of leadership: Looking back to transform forward. In D. V. Day, S. J. Zaccaro \& S. M. Halpin (Eds.), Leader development for transforming organizations: Growing leaders for tomorrow. Mahwah, NJ: Lawrence Erlbaum Associates.

Barling, J., Weber, T., \& Kelloway, E. K. 1996. Effects of transformational leadership training on attitudinal and financial outcomes: A field experiment. The Journal of Applied Psychology, 81: 827-832.

Barsade, S. G. 2002. The ripple effect: Emotional contagion and its influence on group behavior. Administrative Science Quarterly, 47: 644-677.

Bass, B. M. 1985. Leadership and performance beyond expectation. New York, NY: Free Press.

Bass, B. M. 1990. Bass and Stogdill's handbook of leadership: Theory, research and managerial expectations (3rd ed.). New York, NY: Free Press.

Bass, B. M. 1998. Transformational leadership: Industrial, military and educational impact. Mahwah, NJ: Lawrence Erlbaum Associates.

Bass, B. M., \& Avolio, B. J. 1993. Transformational leadership: A response to critiques. In M. M. Chemers \& R. Ayman (Eds.), Leadership theory and research: Perspectives and directions: 49-80. New York, NY: Academic Press.

Bass, B. M., \& Avolio, B. J. 1995. MLQ Multifactor Leadership Questionnaire for research. Redwood City, CA: Mind Garden.

Bass, B. M., \& Riggio, R. E. 2006. Transformational leadership (2nd ed.). Mahwah, NJ: Erlbaum. 
Bell, N. E., \& Staw, B. M. 1989. People as sculptors versus sculpture: The roles of personality and personal control in organizations. In M. B. Arthur, D. T. Hall \& B. S. Lawrence (Eds.), Handbook of career theory: 232-259. Cambridge, England: Cambridge University Press.

Bono, J. E., Foldes, H. J., Vison, G., \& Muros, J. P. 2007. Workplace emotions: The role of supervision and leadership. The Journal of Applied Psychology, 92: 1357-1367.

Bono, J. E., \& Ilies, R. 2006. Charisma, positive emotions and mood contagion. The Leadership Quarterly, 17: 317-334.

Borman, W. C., \& Motowidlo, S. J. 1993. Expanding the criterion domain to include elements of contextual performance. In N. Schmitt \& W. C. Borman (Eds.), Personnel selection in organizations. San Francisco CA: Jossey-Bass.

Boswell, W. R., Olson-Buchanan, J. B., \& LePine, M. A. 2004. The relationship between work-related stress and work outcomes: The role of felt-challenge and psychological strain. Journal of Vocational Behavior, 64: 165-181.

Cavanaugh, M. A., Boswell, W. R., Roehling, M. V., \& Boudreau, J. W. 2000. An empirical examination of self-reported work stress among U.S. managers. The Journal of Applied Psychology, 85: 65-74.

Conger, J. A., \& Kanungo, R. N. 1987. Toward a behavioral theory of charismatic leadership in organizational settings. Academy of Management Review, 12: 637-647.

Conger, J. A., \& Kanungo, R. N. 1994. Charismatic leadership in organizations: Perceived behavioral attributes and their measurement. Journal of Organizational Behavior, 15: 439-452.

Cook, T. D., \& Campbell, D. T. 1979. Causal inference and the language of experimentation. In T. D. Cook \& D. T. Campbell (Eds.), Quasi-experimentation: Design and analysis issues for field settings: 7-9. Boston, MA: Houghton-Mifflin.

Courtright, S. H., Colbert, A. E., \& Choi, D. 2014. Fired up or burned out? How developmental challenge differentially impacts leader behavior. The Journal of Applied Psychology, 99: 681-696.

Crant, J. M., \& Bateman, T. S. 2000. Charismatic leadership viewed from above: The impact of proactive personality. Journal of Organizational Behavior, 21: 63-75.

Crawford, E. R., LePine, J. A., \& Rich, B. L. 2010. Linking job demands and resources to employee engagement and burnout: A theoretical extension and meta-analytic test. The Journal of Applied Psychology, 95: 834-848.

Crum, A. J., Salovey, P., \& Achor, S. 2013. Rethinking stress: The role of mindsets in determining the stress response. Journal of Personality and Social Psychology, 104: 716-733.

Detert, J. R., \& Burris, E. R. 2007. Leadership behavior and employee voice: Is the door really open? Academy of Management Journal, 50: 869-884.

Edwards, J. R., \& Lambert, L. S. 2007. Methods for integrating moderation and mediation: A general analytical framework using moderated path analysis. Psychological Methods, 12: 1-22.

Erez, A., Misangyi, V. F., Johnson, D. E., LePine, M. A., \& Halverson, K. C. 2008. Stirring the hearts of followers: Charismatic leadership as the transferal of affect. The Journal of Applied Psychology, 93: 602-615.

Firth, L., Mellor, D. J., Moore, K. A., \& Loquet, C. 2003. How can managers reduce employee intention to quit? Journal of Managerial Psychology, 19: 170-187.

Fredrickson, B. L., Mancuso, R. A., Branigan, C., \& Tugade, M. M. 2000. The undoing effect of positive emotions. Motivation and Emotion, 24: 237-258.

Fuller, J. B., Patterson, C. E. P., Hester, K., \& Stringer, D. Y. 1996. A quantitative review of research on charismatic leadership. Psychological Reports, 78: 271-287.

Hackman, J. R., \& Oldham, G. R. 1974. The Job Diagnostic Survey: An instrument for the diagnosis of jobs and the evaluation of job redesign projects. Catalog of Selected Documents in Psychology, 4: 148-149.

Hobfoll, S. E. 1989. Conservation of resources: A new attempt at conceptualizing stress. The American Psychologist, 44: 513-524.

Hofmann, D. A., \& Gavin, M. B. 1998. Centering decisions in hierarchical linear models: Implications for research in organizations. Journal of Management, 24: 623-641.

House, R. J. 1977. A 1976 theory of charismatic leadership. In J. G. Hunt \& L. L. Larson (Eds.), Leadership: The cutting edge (a symposium held at Southern Illinois University, Carbondale, October 27-28, 1976): 189-207. Carbondale, IL: Southern Illinois University Press.

House, R. J., \& Howell, J. M. 1992. Personality and charismatic leadership. The Leadership Quarterly, 3: 81-108.

House, R. J., \& Shamir, B. 1993. Toward the integration of transformational, charismatic, and visionary theories. In M. M. Chemers \& R. Ayman (Eds.), Leadership theory and research: Perspectives and directions: 81-107. San Diego, CA: Academic Press.

Hunter, L. W., \& Thatcher, S. M. B. 2007. Feeling the heat: Effects of stress, commitment, and job experience on job performance. Academy of Management Journal, 50: 953-968. 
Jex, S. M. 1998. Stress and job performance: Theory, research, and implications for managerial practice. Thousand Oaks, CA: Sage.

Judge, T. A., \& Piccolo, R. 2004. Transformational and transactional leadership: A meta-analytic test of their relative validity. The Journal of Applied Psychology, 89: 755-768.

Kets de Vries, R. E. 1997. Need for leadership: A solution to empirical problems in situational theories of leadership. Published doctoral dissertation, Tilburg University, The Netherlands.

Kickul, J., \& Posig, M. 2001. Supervisory emotional support and burnout: An explanation of reverse buffering effects. Journal of Managerial Issues, 13: $328-344$.

Lazarus, R. S., \& Folkman, S. 1984. Stress, appraisal, and coping. New York, NY: Springer.

LePine, J. A., LePine, M. A., \& Jackson, C. L. 2004. Challenge and hindrance stress: Relationships with exhaustion, motivation to learn, and learning performance. The Journal of Applied Psychology, 89: 883-891.

LePine, J. A., Podsakoff, N. P., \& LePine, M. A. 2005. A meta-analytic test of the challenge stress-hindrance stressor framework: An explanation for inconsistent relationships among stressors and performances. Academy of Management Journal, 48: 764-775.

Lindell, M. K., \& Whitney, D. J. 2001. Accounting for common method variance in cross-sectional research designs. The Journal of Applied Psychology, 86: 114-121.

Liu, D., Zhang, Z., \& Wang, M. 2012. Mono-level and multilevel mediated moderation and moderated mediation. In X. Chen, A. Tsui \& L. Farh (Eds.), Empirical methods in organization and management research (2nd ed.). Beijing, China: Peking University Press.

Lowe, K. B., Kroeck, K. G., \& Sivasubramaniam, N. 1996. Effectiveness correlates of transformational leadership and transactional leadership: A meta-analytic review of the MLQ literature. The Leadership Quarterly, 7: 385-425.

Lyons, J. B., \& Schneider, T. R. 2009. The effects of leadership style on stress outcomes. The Leadership Quarterly, 20: 737-748.

Mosteller, C. F., \& Tukey, J. W. 1977. Data analysis and regression. Reading, MA: Addison-Wesley.

Muller, D., Judd, C. M., \& Yzerbyt, V. Y. 2005. When moderation is mediated and mediation is moderated. Journal of Personality and Social Psychology, 89: 852-863.

Muthén, L. K., \& Muthén, B. O. 2010. Mplus user's guide. Los Angeles, CA: Muthén \& Muthén.
Ohly, S., \& Fritz, C. 2010. Work characteristics, challenge appraisal, creativity, and proactive behavior: A multilevel study. Journal of Organizational Behavior, 3: $543-565$.

Overman, S. 2011, March 22. Stressed at work? How to move up or out. CNNMoney.com. Retrieved April 5, 2011, from http://management.fortune.cnn.com/tag/ chronic-stress/.

Park, C. L., \& Helgeson, V. S. 2006. Introduction to the special section: Growth following highly stressful life events-current status and future directions. Journal of Consulting and Clinical Psychology, 74: 791-796.

Pearsall, M. J., Ellis, A. P. J., \& Stein, J. H. 2009. Coping with challenge and hindrance stressors in teams: Behavioral, cognitive, and affective outcomes. Organizational Behavior and Human Decision Processes, 109: 18-28.

Piccolo, R., \& Colquitt, J. A. 2006. Transformational leadership and job behaviors: The mediating role of core job characteristics. Academy of Management Journal, 49: 327-340.

Podsakoff, N. P. 2007. Challenge and hindrance stressors in the workplace: Tests of linear, curvilinear, and moderated relationships with employee strains, satisfaction, and performance. Unpublished doctoral dissertation, University of Florida, Gainesville.

Podsakoff, N. P., LePine, J. A., \& LePine, M. A. 2007. Differential challenge stressor-hindrance stressor relationships with job attitudes, turnover intentions, turnover, and withdrawal behavior: A meta-analysis. The Journal of Applied Psychology, 92: 438-454.

Podsakoff, P. M., MacKenzie, S. B., Lee, J., \& Podsakoff, N. P. 2003. Common method bias in behavioral research: A critical review of the literature and recommended remedies. The Journal of Applied Psychology, 88: 879-903.

Preacher, K. J., Rucker, D. D., \& Hayes, A. F. 2007. Assessing moderated mediation hypotheses: Theory, methods, and prescriptions. Multivariate Behavioral Research, 42: 185-227.

Preacher, K. J., Zyphur, M. J., \& Zhang, Z. 2010. A general multilevel SEM framework for assessing multilevel mediation. Psychological Bulletin, 15: 209-233.

Rafferty, A. E., \& Griffin, M. A. 2006. Refining individualized consideration: Distinguishing developmental leadership and supportive leadership. Journal of Occupational and Organizational Psychology, 79: 37-61.

Raudenbush, S. W., \& Bryk, A. S. 2002. Hierarchical linear models (2nd ed.). Thousand Oaks, CA: Sage.

Rodell, J. B., \& Judge, T. A. 2009. Can “good” stressors spark "bad" behaviors? The mediating role of emotions in 
links of challenge and hindrance stressors with citizenship and counterproductive behaviors. The Journal of Applied Psychology, 94: 1438-1451.

Scott, B. A., Garza, A. S., Conlon, D. E., \& Kim, Y. J. 2014. Why do managers act fairly in the first place? A daily investigation of "hot" and "cold" motives and discretion. Academy of Management Journal, 57: 1571-1591.

Seligman, J. P., \& Preacher, K. J. 2008. Monte Carlo method for assessing mediation: An interactive tool for creating confidence intervals for indirect effects [Computer software]. Available from http://quantpsy.org/. Accessed May 2012.

Seltzer, J., Numerof, R. E., \& Bass, B. M. 1989. Transformational leadership: Is it a source of more or less burnout or stress? Journal of Health and Human Resources Administration, 12: 174-185.

Selye, H. 1956. Stress of life. New York, NY: McGraw-Hill.

Shamir, B., House, R. J., \& Arthur, M. B. 1993. The motivational effects of charismatic leadership: A selfconcept based theory. Organization Science, 4: 577-594.

Shamir, B., \& Howell, J. M. 1999. Organizational and contextual influences on the emergence and effectiveness of charismatic leadership. The Leadership Quarterly, 99: 257-284.

Shamir, B., Zakay, E., Breinin, E., \& Popper, M. 1998. Correlates of charismatic leader behavior in military units: Subordinates' attitudes, unit characteristics, and superiors' appraisals of leader performance. Academy of Management Journal, 41: 387-409.

Skakon, J., Nielsen, K., Borg, V., \& Guzman, J. 2010. Are leaders' well-being, behaviours and style associated with the affective well-being of their employees? A systematic review of three decades of research. Work and Stress, 2: 107-139.

Skogstad, A., Einarsen, S., Torsheim, T., Aasland, M. S., \& Hetland, H. 2007. The destructiveness of laissez-faire leadership behavior. Journal of Occupational Health Psychology, 12: 80-92.

Sosik, J. J., \& Godshalk, V. M. 2000. Leadership styles, mentoring functions received, and job-related stress: A conceptual model and preliminary study. Journal of Organizational Behavior, 21: 365-390.

Stroud, C. 2008, September 21. Cracking up? Work related stress can ruin your life, not just your job. The Sunday Times. Retrieved September 24, 2008, from http:/ www.timesonline.co.uk/.

Tedeschi, R. G., \& Calhoun, L. G. 2004. Posttraumatic growth: Conceptual foundations and empirical evidence. Psychological Inquiry, 15: 1-18.

Tepper, B. J. 2000. Consequences of abusive supervision. Academy of Management Journal, 43: 178-190. van Dierendonck, D., Haynes, C., Borrill, C., \& Stride, C. 2004. Leadership behavior and subordinate well-being. Journal of Occupational Health Psychology, 9: 165-175.

van Knippenberg, D., \& Sitkin, S. B. 2013. A critical assessment of charismatic-transformational leadership research: Back to the drawing board? The Academy of Management Annals, 7: 1-60.

Wallace, J. C., Edwards, B. D., Arnold, T., Frazier, M. L., \& Finch, D. M. 2009. Work stressors, role-based performance, and the moderating influence of organizational support. The Journal of Applied Psychology, 94: 254-262.

Walumbwa, F. O., Wang, P., Lawler, J. J., \& Shi, K. 2004. The role of collective efficacy in the relations between transformational leadership and work outcomes. Journal of Occupational and Organizational Psychology, 77: 515-530.

Watson, D., Clark, L. A., \& Tellegen, A. 1988. Development and validation of a brief measure of positive and negative affect: The PANAS scales. Journal of Personality and Social Psychology, 54: 1063-1070.

Webster, J. R., Beehr, T. A., \& Christiansen, N. D. 2010. Toward a better understanding of the effects of hindrance and challenge stressors on work behavior. Journal of Vocational Behavior, 76: 68-77.

Webster, J. R., Beehr, T. A., \& Love, K. 2011. Extending the challenge-hindrance model of occupational stress: The role of appraisal. Journal of Vocational Behavior, 79: 505-516.

Williams, L. J., \& Anderson, S. E. 1991. Job satisfaction and organizational commitment as predictors of organizational citizenship and in-role behaviors. Journal of Management, 17: 601-617.

Yerkes, R. M., \& Dodson, J. D. 1908. The relation of strength of stimulus to rapidity of habit-formation. The Journal of Comparative Neurology and Psychology, 18: 459-482.

Zhang, Y., LePine, J. A., Buckman, B. R., \& Wei, F. 2014. It's not fair... or is it? The role of justice and leadership in explaining work stressor-job performance relationships. Academy of Management Journal, 57: 675-697.

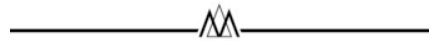

Marcie A. LePine (marcie.lepine@asu.edu) is an associate professor of management and Barrett Honors faculty in the W. P. Carey School of Business, Arizona State University. She received her $\mathrm{PhD}$ in human resources and industrial relations from the Carlson School of Management, University of Minnesota. Her research focuses on the negative and positive effects of stress, leadership, and the worknon-work interface.

Yiwen Zhang (yiwzhang@hku.hk) is an assistant professor of management at the Faculty of Business and Economics 
at the University of Hong Kong. He received his $\mathrm{PhD}$ in management from Arizona State University. His research interests include leadership, work stress, self and identity, employee engagement, and personnel selection.

Eean R. Crawford (eean-crawford@uiowa.edu) is an assistant professor of management and organizations in the Tippie College of Business, University of Iowa. He conducts research on employee engagement, work stress, team effectiveness, social networks, and personality.

Bruce Louis Rich (brich@csusm.edu) is a professor of management at California State University San Marcos. He received his $\mathrm{PhD}$ from the University of Florida. His research interests include employee engagement, prosocial behaviors, and employee well-being.

\section{$M$}

\section{APPENDIX A: CHALLENGE STRESSOR AND HINDRANCE STRESSOR ITEMS}

\section{CHALLENGE STRESSORS:}

1. Having to complete a lot of work.

2. Having to work very hard.
3. Time pressure.

4. Having to work at a rapid pace to complete all of my tasks.

5. Performing complex tasks.

6. Having to use a broad set of skills and abilities.

7. Having to balance several projects at once.

8. Having to multitask your assigned projects.

9. Having high levels of responsibility.

10. A high level of accountability for your work.

\section{HINDRANCE STRESSORS:}

1. Administrative hassles.

2. Bureaucratic constraints to completing work (red tape).

3. Conflicting instructions and expectations from your boss or bosses.

4. Unclear job tasks.

5. Conflicting requests from your supervisor(s).

6. Inadequate resources to accomplish tasks.

7. Conflict with peers.

8. Disputes with coworkers.

9. Office politics.

10. Coworkers receiving undeserved rewards/ promotions. 
Copyright of Academy of Management Journal is the property of Academy of Management and its content may not be copied or emailed to multiple sites or posted to a listserv without the copyright holder's express written permission. However, users may print, download, or email articles for individual use. 